\title{
Novel Strategies for Immunotherapy in Multiple Myeloma: Previous Experience and Future Directions
}

\author{
Ivetta Danylesko, ${ }^{1}$ Katia Beider, ${ }^{1}$ Avichai Shimoni, ${ }^{1}$ and Arnon Nagler ${ }^{1,2}$ \\ ${ }^{1}$ Division of Hematology and Bone Marrow Transplantation, Chaim Sheba Medical Center, \\ Tel Aviv University, Tel Hashomer, Israel \\ ${ }^{2}$ Cord Blood Bank, Chaim Sheba Medical Center, Tel Aviv University, Tel Hashomer, Israel
}

Correspondence should be addressed to Arnon Nagler, arnon.nagler@sheba.health.gov.il

Received 5 December 2011; Accepted 27 February 2012

Academic Editor: Nicolaus Kröger

Copyright (C 2012 Ivetta Danylesko et al. This is an open access article distributed under the Creative Commons Attribution License, which permits unrestricted use, distribution, and reproduction in any medium, provided the original work is properly cited.

Multiple myeloma (MM) is a life-threatening haematological malignancy for which standard therapy is inadequate. Autologous stem cell transplantation is a relatively effective treatment, but residual malignant sites may cause relapse. Allogeneic transplantation may result in durable responses due to antitumour immunity mediated by donor lymphocytes. However, morbidity and mortality related to graft-versus-host disease remain a challenge. Recent advances in understanding the interaction between the immune system of the patient and the malignant cells are influencing the design of clinically more efficient study protocols for MM. Cellular immunotherapy using specific antigen-presenting cells (APCs), to overcome aspects of immune incompetence in MM patients, has received great attention, and numerous clinical trials have evaluated the potential for dendritic cell (DC) vaccines as a novel immunotherapeutic approach. This paper will summarize the data investigating aspects of immunity concerning MM, immunotherapy for patients with MM, and strategies, on the way, to target the plasma cell more selectively. We also include the MM antigens and their specific antibodies that are of potential use for MM humoral immunotherapy, because they have demonstrated the most promising preclinical results.

\section{Introduction}

In spite of recent advances [1, 2], MM remains an incurable disease, and new approaches that induce long-term tumor regression and improve disease outcome are needed.

Autologous stem cell transplantation is a common treatment for MM and results in effective cytoreduction. However, the curative outcome remains elusive due to chemotherapy-resistant disease [3]. A promising route to overcome chemotherapy resistance is the development of immunotherapeutic approaches that target and eliminate myeloma cells more selectively.

A critical indication that immunotherapy is effective is that tumor-associated antigens (TAAs) are expressed in the tumor cells if disease reemerges after therapy. Vaccination strategies targeting single antigens and whole-cell approaches have shown promise in clinical studies.
They also have the advantage of presenting patient-specific and potentially unidentified antigens to immune effector cells.

Monoclonal antibodies (mAbs) have been evaluated in preclinical and clinical studies. Potential mAb candidates include growth factors and their receptors, other signalling molecules, and antigens expressed exclusively or predominantly on MM cells. Therapy with mAb may involve a range of mechanisms, including antibody-dependent cellular cytotoxicity (ADCC), complement-dependent cytotoxicity (CDC), interference with receptor-ligand interactions, and $\mathrm{mAb}$ conjugation to radioisotopes or toxins [4].

Effector cell dysfunction and the increased number of regulatory $\mathrm{T}$ cells in patients with malignancy may limit the efficacy of immunotherapeutic approaches. Strategies to improve immunotherapy for MM involve the depletion of $\mathrm{T}$ 
regulatory cells, combining active and passive immunotherapy, the use of cytokine adjuvants, and using immunotherapy in conjunction with autologous and allogeneic transplantation.

The unique value of immunotherapy, in allogeneic transplantation, is the graft-versus-disease effect mediated by alloreactive lymphocytes, which attack the tumor.

However, the significant morbidity and mortality due to regimen-related toxicity and graft-versus-host disease (GvHD) pertain [5].

Immunotherapy is promising area of investigation that focuses on developing strategies to elicit myeloma-specific immune responses to eliminate the malignant plasma cell selectively.

\section{Tumor-Specific Immunity and Immune Evasion: The Role of the Adoptive and Innate Immune System in Controlling MM}

MM is associated with a variety of immune defects; therefore, immunotherapy is particularly challenging. It is considered, at least to a certain extent, to be controlled by the adaptive immune system. This hypothesis is supported by the fact that the therapeutic effect of alloSCT is mediated in part by immune effects exerted by donor-derived $\mathrm{T}$ cells and that donor T cells infused into MM patients are capable of inducing remission in case of relapse [6,7].

The development of effective tumor-specific immunotherapy requires addressing several basic issues concerning tumor cell biology and the complex interaction between cancer cells and host immunity.

Tumor cells may evade host immunity through a variety of mechanisms. Some may contribute to myeloma cell "tolerance," including myeloma-derived cytokines such as transforming growth factor-b (TGF-b), which suppresses B cells and $\mathrm{T}$ cells via inhibition of interleukin-2 (IL-2) autocrine pathways, inadequate antigen presentation, resistance to NK cell lysis, and defective T, B, and NK cells [8]. Much data suggests that early-stage cancers are eliminated by immune surveillance, whereas established tumors are more likely to induce immune tolerance [9].

Tumor-specific CD4+ T cells have a central function in the immune response against cancer $[10,11]$. Early studies in rats and mice indicated that adoptive transfer of tumourspecific CD4+ $\mathrm{T}$ cells may be very efficient in eradicating established cancers $[12,13]$. CD4 $+\mathrm{T}$ cells are required for activation of tumour-specific cytotoxic CD8+ T cells [14], but they can also eradicate cancer in the absence of CD8+ $\mathrm{T}$ cells $[15,16]$. Tumor-specific CD4+ $\mathrm{T}$ cells recognize antigenic peptides presented by MHC class II molecules. However, most cancer cells are MHC class II negative and therefore cannot be directly recognized by CD4+ T cells. Tumor-specific CD4+ T cells overcome this obstacle by collaborating with macrophages and dendritic cells [17]. These professional antigen-presenting cells endocytose TSA, process it, and display antigenic peptides on their MHC class II molecules for recognition by tumor-specific $\mathrm{CD} 4+\mathrm{T}$ cells $[10,18,19]$. The number and function of $\mathrm{T}$ cell subsets were reported to be abnormal in patients with MM. The CD4:CD8 ratio inverted, and the Th1:Th2 ratio among CD4+ cells is abnormal [20]. T cells from MM patients were shown to function aberrantly [21]. In addition, the levels of expression of CD28 and cytotoxic T lymphocyte-4 (CTLA-4) costimulatory molecules required for $\mathrm{T}$ cell activation and inhibition, respectively, were downregulated in T cells derived from MM patients [22]. Tumor cells express a variety of factors that suppress the function and development of APCs and T cells. The B7 family of cosignaling molecules is expressed on the surface of $\mathrm{T}$ lymphocytes and is crucial for their optimal activation, as well as for the prevention of immunologic tolerance. These cosignaling molecules not only provide critical positive signals that stimulate $\mathrm{T}$ cell growth, upregulate cytokine production, and promote $\mathrm{T}$ cell differentiation but also contribute key negative signals that limit, terminate, and/or attenuate $\mathrm{T}$ cell responses $[23,24]$.

Although the antibodies may trigger direct antitumor activity through their Fab2 portion causing apoptosis of tumor cells [25], they more often mediate damage of cancer cells by recruiting other effector systems of innate immunity through their Fc portion. Such effector cells include mononuclear and polymorphonuclear leukocytes that phagocytise opsonized tumor cells and NK cells primarily involved in the process of ADCC [26]. Complement is the other soluble effector system of innate immunity that can be recruited by mAbs to control tumor growth CDCC $[27,28]$.

The role of innate effector cells, such as macrophages, NK cells, NKT cells, and $\gamma \delta \mathrm{T}$ cells, in natural tumor immunity and tumor immunotherapy has been revisited $[29,30]$. NK cells are cytotoxic lymphocytes that have the ability to lyse certain tumor and virus-infected cells, without prior immunization [31]. The cytotoxic activity of NK cells is tightly controlled by a balance between activating and inhibitory signals from receptors on the cell surface [32]. Activating receptors include the natural cytotoxicity receptors and NKG2D, all of which push the balance toward cytolytic action through engagement with separate ligands on the target cell surface [32]. The role of autologous NK cells in the immune recovery, which is a strong prognostic indicator for survival after autologous stem cell transplantation (ASCT), was highlighted by Porrata et al. [33], who showed that reinfusion of autologous NK cells correlates with absolute lymphocyte recovery after ASCT for MM and non-Hodgkin's lymphoma.

Defective NK cells have also been noted in patients with MM [34]. This is of major importance since NK cells have antimyeloma activity $[35,36]$. In the setting of AlloSCT for $\mathrm{MM}$, there is emerging evidence that donor NK cells along with donor Tlymphocytes exhibit anti-MM activity [37]. In another study, it was shown that, after coincubation of NK cells from normal volunteers with myeloma cells from three different $\mathrm{MM}$ cell lines and fresh $\mathrm{BM}$ samples from nine myeloma patients, myeloma cells were susceptible to NK cell lysis, even in the absence of IL-2 [36]. Of note, CD34 hematopoietic stem cells, as well as peripheral blood mononuclear cells (PBMNCs), were completely resistant to NK cell killing under similar conditions [36]. Recently, it has been shown that autologous NK cells from myeloma patients 
expanded ex vivo with IL-2 displayed significant cytotoxic activity against primary autologous plasma cells [38]. Furthermore, it has been demonstrated that the infusion of haploidentical killer-cell immunoglobulin-like receptor (KIR) ligand-mismatched NK cells in the autologous MM setting resulted in 50\% near complete remission of relapsed MM patients [39]. However, ex vivo or in vivo expansion of the NK cells with IL-2 carries a dose-limiting toxicity.

The role of dendritic cells (DCs) is dichotomous; they may present both antigens, appropriate stimulator molecules to initiate an adaptive immune response, or they may induce tolerance and release anti-inflammatory signals. Circulating DCs from MM patients were shown to be dysfunctional because they failed to upregulate costimulatory molecules required for activation [40]. It was suggested that a reduced function of DCs indicates the progression of the disease [40]. Cytokines, such as IL-6, TGF-b, IL-10, and vascular endothelial growth factor (VEGF), which were actively produced by myeloma cells [40] and were found to be in the tumor microenvironment as well as in the serum [41], played a role in preventing the development of functional DCs. Furthermore, DCs from MM patients had reduced phagocytic capacity [42]. In addition, monocyte-derived DCs exhibited downregulated expression of activation markers and impaired presentation capacity to T cells [41]. Impaired activity of DCs may be linked to the upregulation of Tregs [43]. $\mathrm{T}$ cell tolerance to tumor-associated antigens plays a significant role in immune evasion by tumors [44, 45]. Naturally occurring and adaptive regulatory $\mathrm{T}$ cells (Tregs) are anergic cells with suppressive capabilities that constitute $5-10 \%$ of CD4 cells. These cells are induced early during tumor development and were shown to contribute to tumor tolerance $[46,47]$.

The presence of Tregs in tumors is associated with a poor prognosis [48]. Patients with many different types of cancers had increased numbers of Tregs in their blood, tumor mass, and draining lymph nodes $[49,50]$. Increased numbers of Tregs were found in patients with MM as well [51-53]. Therapeutic approaches for breaking tolerance to tumor cells have been tried; the depletion of Tregs is the most studied strategy [54-56]. Nevertheless, despite the tumor antigen-specific immunity [57], the tumors were not completely rejected [58]. Thus, it is essential to reveal the mechanism leading to Treg expansion for developing strategies to eliminate them and to improve the results of cancer immunotherapy [59].

There is also emerging evidence that the cellular bone compartment affects MM cell growth and progression. This is supported by the observation that osteoclasts can support long-term survival and proliferation of primary MM cells $[60,61]$, and osteoblasts (OB) may impede MM cell growth $[62,63]$. Thus, targeting these cellular elements may also favorably affect disease control. The BM microenvironment in $\mathrm{MM}$ controls the tumor growth, myeloma cell survival $[64]$ and drug resistance $[65,66]$. In turn, MM cells were suggested to modify the BM microenvironment in which they reside in several ways including induction of osteoclastogenesis and suppression of osteoblast activity, both leading to impaired bone formation [67]. BM-derived mesenchymal stromal cells (MSCs) are precursors of osteoblasts and preferentially differentiate into bone forming cells upon in vitro culture and in vivo introduction. MM cells were suggested to target MSCs thereby diverting their functions to serve the MM cells. This idea led to studies of the functions of MSCs derived from MM patients (MM-derived MSCs) compared to those of healthy individuals; it was suggested that MSCs from myeloma patients exhibit defective functions [6870]: MM-derived MSCs were reported to exhibit decreased colony-forming unit number [70], growth impairment [70], reduced osteogenic differentiation [68] and increased IL-6 secretion $[68,70]$.

To summarize, the task of developing effective immunotherapy for cancer relies on the identification of appropriate tumor targets, the augmentation of antigen-presenting and effector cell function, and the reversal of the tumor-mediated immunosuppressive state [71]. In this review we focus on MM antigens and their specific antibodies, which have demonstrated the most promising results in preclinical studies and are therefore the best candidate for future MM humoral immunotherapy.

\section{Myeloma-Specific Antigens and Vaccines: Idiotype-Preclinical Studies}

The myeloma-specific antigen that can be targeted by immunotherapy is the idiotype (Id) protein representing the variable segment of the monoclonal immunoglobulin generated in the plasma cell clone [72]. Targeting of the idiotype protein by humoral or cellular immune mechanisms, in preclinical models, results in death of the tumor cells and disease regression. Induction of protective antitumor immunity through immunization with a myeloma idiotype has been most extensively studied with the murine plasmacytoma MOPC-315 model. In this model, it was shown that weekly immunizations with tumor-derived paraprotein protect syngeneic mice against a subsequent challenge with MOPC-315 cells [73]. Idiotype-specific $\mathrm{T}$ cells at a low frequency were detected in $90 \%$ of patients with MM or MGUS [74, 75]. In addition, transfer of idiotype-specific CD4+ $\mathrm{T}$ cells has been shown to be protective against tumor challenge [76]. Antigen-specific responses, of both CD4 and CD8 positive T cells, upon in vitro stimulation with autologous paraprotein have been described in patients with monoclonal gammopathies [74]. Induction of cytotoxic $\mathrm{T}$ cell activity against autologous myeloma cells was also shown for stimulation with idiotype-loaded dendritic cells [77, 78]. Consistent with these results, several authors have shown that $\mathrm{T}$ cells in myeloma patients respond to peptides corresponding to complementarity-determining region I-III of heavy and light chains of the autologous M-component $[79,80]$. Yi found [81] that idiotype-induced $\mathrm{T}$ cell stimulation was mainly confined to the CD4+ subset in most of the patients examined and was MHC class II restricted. Idiotype-specific $\mathrm{CD} 8+\mathrm{T}$ cells were also demonstrated, but at a lower frequency. Idiotype-specific CD4+ and CD8+ T cells were mainly of the type 1 subsets, as judged by their secretion of interferon (IFN) $-\gamma$ and interleukin (IL)-2 [82, 83]. Moreover, the number of individuals who had an idiotype-specific response 
of the T-helper-1 (Th1) type (IFN- $\gamma$ - and/or IL-2-secreting cells) [84] was significantly higher for patients with indolent disease (MGUS and MM stage I) than for those with advanced MM (stage II/III). In contrast, cells secreting the Th2subtype cytokine profile (IL-4 only) [84] were observed more frequently in patients with advanced MM (stage II/III) [75].

Collectively, these findings indicate that the existing idiotype-specific immune response is too weak to control the growth of myeloma cells in vivo. It is possible that a shift from an idiotype-specific type- 1 response, that is, Th1 and T cytotoxic-1 (Tc1) [85], in early MM to a type 2 response (Th2 and probably Tc2) [85] in advanced disease occurs. These studies provide indirect evidence that idiotype-specific T cells may have a regulatory impact on human tumor B cells.

\section{Clinical Trials of Idiotype Vaccination for MM}

Native idiotype protein can be obtained from the serum of myeloma patients, making vaccination trials relatively easy. Injection of paraprotein alone may lead to an increased cellular and humoral immune responses, but it seems insufficient to generate sustained antimyeloma immunity [86]. Intradermal injections of paraprotein, combined with subcutaneous administration of GM-CSF at the same site, induced an increase in the numbers of IFN $\gamma$ - and IL-2-secreting T cells [87]. This response was present in CD4+ and CD8+ T cell subsets and could be inhibited by blockade of MHC class I molecules. Furthermore, production of idiotype-specific IgM was induced in vivo. However, there was no clear indication of clinical efficacy since the paraprotein levels remained essentially unchanged, and DTH (delayed-type hypersensitivity reaction) responses to idiotype protein were not detected.

In contrast, in subcutaneous vaccination with keyhole limpet haemocyanin (KLH)-coupled paraprotein and additional adjacent injections of GM-CSF in patients after a highdose chemotherapy and ASCT, DTH reactions to the vaccine were induced in $85 \%$ of patients, but in vitro testing provided little evidence for specific T cell immune responses [88, 89].

A potential concern with the use of idiotype-based vaccination approaches in MM is that plasma cells only express the idiotype protein weakly, and idiotype may be associated with the development of tolerance. One strategy for targeting myeloma by host effector cells is the genetic manipulation of $\mathrm{T}$ cells such that the idiotype antibody is expressed and induces signalling via the $\mathrm{T}$ cell receptor.

When patients in stage I disease were immunized with idiotype in conjunction with IL-12 +/- GM-CSF, there was a decrease in circulating clonal cells as detected by quantitative PCR monitoring in four of six patients [90]. Finally, intradermal immunization with uncoupled recombinant idiotype in conjunction with GM-CSF induced idiotype-specific T cell reactivity in a patient with advanced myeloma [91].

Idiotype-loaded dendritic cells (DCs) have been used by various groups as vaccines in MM patients, mostly in the setting of clinical remission after autoSCT [92-96]. Although the patient characteristics and vaccine particularities preclude firm comparisons between these trials, they nevertheless have collectively shown that the induction of cellular immune responses is possible in the setting of minimal disease burden after ASCT. However, no real evidence has been obtained in these Phase I and II trials that the natural course of the disease has been altered by idiotype vaccination, and efforts to improve the immunogenicity of the vaccination are ongoing.

\section{Myeloma-Specific Tumor Antigens}

A variety of tumor-associated antigens have been identified in myeloma cells that may be targeted selectively by the immunity of the host. These include the cancer testis (CT) antigens, MUC1, HM1.24, CYP1B1, SP17, PRAME, Wilms' tumour 1 (WT1), and heat shock protein gp96 [97-102].

MUC1 is a physiologically highly glycosylated epithelial mucin. Since the molecule is often expressed but severely underglycosylated on malignant cells, it may be recognized by cytotoxic T cell lymphocyte (CTL) toxicity in a MHC-unrestricted manner [103]. This effect has also been shown in myeloma [104]. Furthermore, HLA class-I-restricted peptide target epitopes have also been identified within the MUC1 sequence, and the majority of myelomas appear to express and present these epitopes to T cells [97].

WT1 is a zinc finger transcription factor with overexpression in myeloid malignancies $[105,106]$. While WT1 is also frequently expressed, albeit at lower level, in lymphoid malignancies, myeloma cells may be efficiently recognized and lysed by WT1-specific CTL [107].

CD317/HM1.24, a cell surface protein involved in cell signaling [108], is another potential tumor-associated antigen overexpressed in MM [109]. HM1.24-specific CTL can be induced in healthy volunteers and MM patients [110].

Recently, it has been shown that the pituitary tumor transforming gene 1 is expressed aberrantly in multiple myeloma and may serve as a target for cellular immunotherapy [111].

The RHAMM is an immunogenic antigen that is strongly expressed in several hematologic malignancies [112, 113] and induces humoral and cellular immune responses [114119 ].

CT antigens represent a family of proteins that are expressed in a variety of tumors, while their presence in normal tissue is limited to the testis and placenta. Several groups have described that CT antigens are also expressed by myeloma cells [98, 120-125].

CT antigens are commonly capable of inducing antibody-mediated and T cell-mediated immunity in MM patients [100]. CT Ag-specific T cells can be detected in the blood of myeloma patients and appear to be functionally competent $[124,126]$. Depending on the patient population and the method used to detect CT gene expression, there appears to be a trend towards higher likelihood of expression with advanced stage $[121,123]$ and presence of cytogenetic abnormalities [124], both representing adverse prognostic factors in myeloma. These antigens represent potential markers for minimal residual disease (MRD) after ASCT and could also be used to target myeloma cells remaining in the patients' BM after standard therapy. In addition, in MM, 
expression of CT antigens has been shown to be strongly correlated to the clinical outcome; that is, the presence of CT antigens expression has been linked to shorter survival [127].

Baseline expression frequencies, measured by RT-PCR, determined MAGE-C1/CT7 as the most frequently detected antigen, possibly perform a gatekeeper function for the other antigens examined. Importantly, $80 \%$ of the patients with a significant number of plasma cells expressed at least one of these antigens investigated [128].

A novel CT antigen, ropporin, is a testis-specific protein localized in the sperm flagella. Comparing ropporin expression in healthy and MM samples, ropporin expression positive signals were found in $44 \%$ of the MM primary samples. The immunogenicity of ropporin was confirmed by the presence of specific antibodies detected by enzyme-linked immunosorbent assay in patients' serum [129].

The gene expression of CT antigen in relapse samples and in newly diagnosed MM cases was evaluated [130, 131]. The $\mathrm{CT}$ antigen expression after treatment was shown for a limited number of CT antigens including PASD1, CTAG1B, and MAGEC1/CT7 [123, 124, 128, 132, 133]. Multivariate analysis demonstrated that for the set of newly diagnosed cases shorter overall survival was associated with the presence of MAGEA6 and CDCA1, and MAGEA9 was associated with a shorter overall survival in [130]. In the set of the relapse cases, the presence of CTAG2 was associated with a shorter progression free-survival and the presence of SSX1 with shorter overall survival [130].

NY-ESO-1 is the most immunogenic of the CT antigens [99]. NY-ESO-specific CTLs generated from patients with MM were shown to kill primary myeloma cells, normal cells pulsed with a NY-ESO-1 peptide, but not normal cells pulsed with an irrelevant peptide. Spontaneous humoral and CD8 - T cell-mediated responses to NY-ESO-1 have been identified in patients with advanced disease $[99,124,126]$. Vaccination strategies targeting NY-ESO-1 may be effective at inducing specific antimyeloma immunity, and a clinical trial evaluating the efficacy of an NY-ESO peptide vaccination given in conjunction with GM-CSF is underway [99].

Importantly, the finding that immune responses against CT antigens are induced by alloSCT [100] suggests that this class of tumor antigens might indeed represent natural targets for donor-derived alloimmune or even spontaneous antimyeloma immune responses. Interestingly, in patients undergoing an allogeneic transplantation, antibody responses to NY-ESO-1 were detected after transplantation, suggesting that this may represent a target for the graft-versus-myeloma effect. LAGE-1 mRNA was detected in $49 \%$ of MM patients [134]. Recently, de Carvalho et al. reported that LAGE-1a mRNA was more frequent than LAGE-1b expression in MM cases [135]. The LAGE-1a protein has $84 \%$ similarity with the NY-ESO-1 protein, and the authors identified seven peptides present in both CTAs that were recognized by $\mathrm{T}$ lymphocytes in different tumors. Because spontaneous humoral immunity against NY-ESO-1 was not detected before the allogeneic transplant in previous study [100], the LAGE- 1 a isoform and NY-ESO- 1 could be considered as one "single" CTA for immunotherapy purposes [135].
Currently, an immunotherapy trial targeting the CTAs MAGE-A3 and NY-ESO-1 in MM patients is in progress (NCT00090493).

\section{Cell-Based Myeloma Vaccines}

Instead of vaccinating myeloma patients against TAs, an alternative principle aims at stimulating the immune system with the entirety of the myeloma cell's antigens [136]. Such approaches may be implemented by using tumor cell lysates or apoptotic tumor cells as a source for antigens. In a direct comparison, irradiated, apoptotic tumor cells appear to be a superior source for antigen compared to tumor lysates for DC-mediated T cell stimulation [137]. Indeed, stimulation of $\mathrm{T}$ cells from the peripheral blood or bone marrow with autologous dendritic cells that had been coincubated with purified, irradiated myeloma cells may give rise to $\mathrm{T}$ cell lines with specific IFN- $\gamma$ production and lytic activity of primary autologous tumor cells. In this approach, presentation of antigens from myeloma cell lines by DC $s$ is greatly enhanced by coating of myeloma cells with a specific antibody such as anti-CD138 [138]. Similar results with induction of specific, cytotoxic $\mathrm{T}$ cell activity against autologous myeloma cells have also been reported when DCs were loaded with myeloma cells lysed by repetitive freeze-thaw cycles [139].

Among the leukemia-associated antigens (LAAs), RHAMM, proteinase 3, and WT-1 have been already tested for clinical peptide vaccination $[116,140]$. A Phase I/II R3 peptide vaccination for patients with AML, MDS, and MM overexpressing RHAMM was initiated [141]. Patients with a diagnosis of MM were included who fulfilled the following criteria: partial remission (PR) or near-complete remission (NCR) after a high-dose chemotherapy with melphalan and ASCT; immunofixation still positive; free light chains in serum and/or urine were detectable. The patients expressed both RHAMM and HLA-A2 as assessed by RT-PCR and flow cytometry. Authors found a significant increase of specific CD8+ $\mathrm{T}$ cells recognizing the RHAMM-R3 peptide in 4/9 patients by ELISpot analysis and/or by tetramer staining. However, due to the number of patients in this Phase I trial no meaningful statistical analysis could be performed.

The interaction between the CD40 ligand $(\mathrm{CD} 40 \mathrm{~L})$ on activated T lymphocytes and CD40 on the APCs has been shown to be crucial for the induction of cytotoxic T lymphocyte (CTL) immunity. CD40-B cells can be generated in large numbers from small amounts of peripheral blood and have the potential to serve as a cellular adjuvant for immunotherapy [142]. The CD40-B cells loaded with tumor lysates induced strong target-specific CTLs, based on large numbers of IFN- $\gamma$ - secreting cells and higher cytotoxic activity against target cells compared to the CD40-B cells without the tumor lysates [142].

Recently, hTERT (human telomerase reverse transcriptase) was detected in the majority of human malignancies. HTERT can be a target for CT-T lymphocytes in several malignancies including $\mathrm{MM}$ in vitro [143] and in vivo [144]. Kryukov et al. studied antigen-specific and HLA-A2-restricted cytotoxic activity against an ARH77 myeloma cell line 
in vitro [145], when HLA-A2-specific hTERT-derived nonapeptide was used as a TAA. Myeloma-specific cytotoxic activity of hTERT-reactive CTLs was established by repeated stimulation of the CTLs via DCs loaded with hTERT-derived nonapeptide.

In cancer immunotherapy, including $\mathrm{MM}$, there is no proof that a cancer vaccine has to stimulate a large number of $\mathrm{T}$ cells in order to initiate tumor rejection. T cell responses to tumor antigens may be of a low level, and negative results obtained with most ex vivo assays may not exclude the beneficial effect of tumor-specific T cells in vivo. After stimulation, myeloma-reactive T cells activate and produce IFN- $\gamma$. Such activated $\mathrm{T}$ cells can be efficiently expanded in vitro without loss of specificity to the target myeloma antigens. Cytotoxicity of expanded myeloma-reactive $\mathrm{T}$ cells was evaluated and demonstrated a strong and myeloma-specific response which, as expected, was mainly CD8+ CTL dependent [146]. Further expansion of sorted myeloma-reactive $\mathrm{T}$ cells containing both helper and cytotoxic $\mathrm{T}$ cells does not lead to loss of antigen specificity but, rather, leads to potentiation of cytotoxicity, probably via beneficial cytokine production by helper $\mathrm{T}$ cells that positively influences further proliferation and the cytotoxic potentiality of CD8+ CTLs. Immunization with MUC1 protein results in activation of CT-T lymphocytes both in vitro and in vivo [147]. After immunization with this antigen, activated $\mathrm{T}$ lymphocytes were separated immunomagnetically and expanded in vitro [148]. Specific cytotoxicity of the expanded $\mathrm{T}$ lymphocytes was tested against a myeloma cell line [148]. Such an approach can also be useful therapeutically as, after enrichment, myelomareactive $\mathrm{T}$ cells can be expanded in vitro to reach amounts useful and effective in clinical trials. An approach which was recently introduced into the clinical setting relies on adoptive transfer of $\mathrm{T}$ cells expressing transgenic $\mathrm{T}$ cell receptors (TCRs) with antitumor function; however, there is a critical bottleneck in identifying high-affinity TCR specificities necessary for treatment of various malignancies [149].

In general, the process of identification and characterization of individual myeloma specific $\mathrm{T}$ cell clones can be used as a tool for immune monitoring during cancer treatment.

Depletion of CD25+ regulatory $\mathrm{T}$ cells by specific monoclonal antibodies like denileukin diftitox (Ontak; [150]) or addition of toll-like receptor stimulation oligodinucleotides might pave the road for new approaches in the field of peptide vaccination [151]. Moreover, advances are being made in the combination of peptide vaccination with alloSCT [140].

\section{Vaccines for Myeloma Based on Dendritic Cells}

Preclinical studies have shown that DCs generated from myeloma patients were functional and could efficiently present Id determinants to autologous T cells $[83,152]$. DCs pulsed with Id protein can be used to induce the type-1 anti-Id response in myeloma patients. Wen and coworkers [79, 95] reported results from vaccinating an MM patient with autologous Id protein-pulsed DCs generated from blood adherent cells. An immune response against Id was demonstrated in many of the patients. A minor clinical response (25\% reduction in the M-component) was observed in one patient and stable disease in the remaining patients. Cull and coworkers [153] reported on vaccinating two patients with advanced refractory MM with Id-pulsed DCs combined with GM-CSF. An anti-Id T cell proliferative response was detected in both patients, which was associated with IFN- $\gamma$ production by the $\mathrm{T}$ cells. One patient also had an anti-Id humoral response. Subcutaneous DC vaccination indeed induces better antimyeloma responses than intravenous DC vaccination [154-156].

DC vaccines can also be produced in the form of fusion of tumor cells with DCs. Vaccination with fusions of tumor cells and DCs is an effective treatment in animal tumor models [157]. In a murine plasmacytoma model, vaccination with DCs fused with mouse 4 TOO plasmacytoma cells was associated with induction of antitumor humoral and CTL responses [158]. Immunization with the fusion cells protected mice against tumor challenge and extended the survival of tumor-established mice without eradication of the tumor cells. Addition of IL-12 helped eradicate the established tumor. In a more recent study, human myeloma cells, either primary myeloma cells from patients or a myeloma cell line U266, were fused to human DCs [159]. Fusions with mature rather than immature DCs induced higher levels of $\mathrm{T}$ cell proliferation and activation, as assessed by intracellular IFN- $\gamma$ expression, and stronger CTL activity against the tumor cells $[160,161]$.

Based on these results, a clinical trial was designed to evaluate the efficacy of vaccinating myeloma patients with a fusion of myeloma cells and autologous mature DCs [159].

However, patients with MM have DCs that are functionally defective [42]. In order to generate potent functional DCs, alternative methods for blocking some inhibitory signals have been tested $[41,162]$. It was reported that the inhibitory factors and abnormal signaling pathways of DCs during maturation with tumor antigen might be responsible for the defective activity of DCs in MM and suggested that the way to overcome these abnormalities is by neutralizing the signaling that would lead to suppressing the immune response [163]. In an attempt to increase DC potency by the use of cytokine combinations, alpha-type-1-polarized DCs $(\alpha \mathrm{DC} 1 \mathrm{~s})$ that are induced to mature using the $\alpha \mathrm{DC} 1$-polarizing cytokine cocktail (interleukin (IL)-1 $\beta$, tumor necrosis factor (TNF) $-\alpha$, interferon (IFN) $-\alpha$, IFN- $\gamma$, and polyinosinic:polycytidylic acid [poly(I:C)]) can be developed to generate strong functional CTLs in several diseases, compared to standard DCs (sDCs) [164]. When mononuclear cells (MNCs) from the BM are used as a source of tumor antigen, the DCs usually show weak antigenicity due to possible contamination with normal cells. To overcome this problem, the previous report demonstrated that DCs pulsed with purified and optimized myeloma antigen could generate potent myeloma-specific CTLs [165]. Recently, the possibility of cellular therapy using autologous $\alpha \mathrm{DC} 1$ pulsed with the ultraviolet $\mathrm{B}$ (UVB)-irradiated allogeneic myeloma cell line, ARH77 with HLA-A0201+, which could generate myeloma-specific CTLs against autologous myeloma cells was investigated [166]. 
Vaccination with DC/tumor fusions induces antitumor immunity in the majority of the patients; however, the responses are transient and not always associated with clinical benefit. One potential limiting factor is the regulatory $\mathrm{T}$ cells. Developing strategies that promote the expansion of functionally competent tumor reactive $\mathrm{T}$ cells and limit the influence of regulatory $\mathrm{T}$ cells is necessary to improve the efficacy of the DC/MM fusion vaccine. One approach is vaccination in conjunction with ASCT which facilitates vaccine response by inducing a minimal residual disease state and limiting the inhibitory influence of the myeloma cells. In preclinical models, stem cell transplantation results in the in vivo depletion of regulatory $\mathrm{T}$ cells, transient loss of tumor mediated tolerance, and enhanced capacity to respond to tumor vaccines $[167,168]$.

PD-1 expression is upregulated on T cells isolated from patients with MM, and PD-1 blockade is associated with enhancement of $\mathrm{T}$ cell response to the vaccine. Luptakova et al. examined the effect of lenalidomide on $\mathrm{T}$ cell activation and polarization, PD-1 signaling, and vaccine-induced responses in vitro [169]. In vitro exposure to lenalidomide results in enhanced $\mathrm{T}$ cell activation in response to direct ligation of the costimulatory complex and stimulation by the $\mathrm{DC} /$ myeloma fusion vaccine, suppressed $\mathrm{T}$ cell expression of PD-1 and regulatory T cells, 2 critical pathways responsible for tumor-mediated immune suppression. This is the first demonstration of an interaction between lenalidomide and the PD-1/PDL-1 pathway. These findings support the development of cellular immunotherapy in conjunction with lenalidomide, including its use with the DC/myeloma fusion vaccine [169]. Lenalidomide resulted in greater degree of Th1 polarization as manifested by a 2 -fold increase in the percentage of CD8+ T cells expressing IFN- $\gamma(P=0.02)$ and a decrease in the percentage of regulatory $\mathrm{T}$ cells from $6.88 \%$ to $3.13 \%(P=0.02)$. In addition, the percentage of NK cells expressing IFN- $\gamma$ was 5 -fold greater $(P=0.03)$ in the presence of lenalidomide.

Lastly, Luptakova et al. found that vaccination with fusion-mediated stimulation of autologous $\mathrm{T}$ cells in the presence of lenalidomide resulted in an increase in the percentage CD4+ and CD8+ T cells expressing IFN- $\gamma(5.35 \%$ to $8.79 \%, P=0.06$, and $6.37 \%$ to $9.85 \%, P=0.03$, resp.). The proportion of regulatory $\mathrm{T}$ cells decreased from $9.57 \%$ to $4.43 \%$ in the presence of lenalidomide $(P<0.01)$. As with nonspecific stimulation, PD-1 expression on CD4+ cells in the presence of lenalidomide decreased from $24 \%$ to $19 \%$. In concert with these findings, exposure to lenalidomide resulted in increased cytotoxic T lymphocyte-mediated lysis of autologous tumor targets (from $25 \%$ to $36 \%$ ). At this time several clinical studies recruit patients for clinical investigation [169].

\section{NK Cells}

DCs and NK cells reciprocally activate each other during the immune response. DCs can stimulate NK cells to produce interferon- $\gamma$ (IFN- $\gamma$ ) and to expand NK cells in vitro $[170,171]$. Reversely, the DCs can be activated by NK cells to increase the production of cytokine, costimulatory molecules expression, and $\mathrm{T}$ cell stimulation, resulting in a more efficient Th1-type polarization and CTL generation [172, 173]. Nguyen-Pham et al. investigated the possibility of generating potent DCs through stimulation with NK cells in the presence of different cytokines in order to induce myeloma-specific CTLs against MM in vitro [174]. They demonstrated that potent DCs can be generated by stimulation with NK cells, as activator helper cells, in the presence of TLR3 agonists, IFN- $\gamma$, and IL-2. NK cell-stimulated DCs exhibited high expression of costimulatory molecules and high production of IL-12p70 [174]. These DCs induce high potency of Th1 polarization and exhibit a high ability to generate myeloma-specific CTL responses. These results suggest that functionally potent DCs can be generated by stimulation with NK cells and may provide an effective source of DC-based immunotherapy in multiple myeloma [174].

Recently, it has been shown that autologous NK cells from myeloma patients expanded ex vivo with IL-2 displayed significant cytotoxic activity against primary autologous plasma cells [38]. However, ex vivo or in vivo expansion of the NK cells with IL-2 carries a dose-limiting toxicity.

The potential of tumor-activated (TaNK) cells to induce lysis has been explored [175]. Recent study was designed to assess the relative function in vitro of NK and TaNK cells from MM patients compared to normal healthy controls in the lysis of tumor cell lines and freshly isolated primary autologous and allogeneic MM cells [175]. In this study, the authors demonstrated that TaNKs from myeloma patients can induce a substantial lysis of myeloma cell lines as well as autologous and allogeneic freshly isolated BM malignant plasma cells. This was in accordance with the degree of killing reported in the study by Alici et al. [38], where NK cells underwent ex vivo expansion with the addition of IL-2. This potential is not affected either by the disease status or by the antimyeloma treatment, including novel agents and dexamethasone. These findings provide information for the use of TaNK cells in MM therapy and particularly in combination with the novel agents.

Modulation of inhibitory and activating NK receptor ligands on tumor cells represents a promising therapeutic approach against cancer, including MM. Proteasome inhibitors, in particular lactacystin, that most probably target inhibitory KIR ligand class I on the MM tumor cells may contribute to the activation of cytolytic effector NK cells in vitro, enhancing their antimyeloma activity [176].

Several reports showed a reciprocal relationship between NK and Tregs [177]. In addition Tregs could suppress the function of NK cells [178]. A unique mouse model of MM, namely, 5T2MM-bearing mouse, was useful for elucidating the pathophysiological mechanisms underlying the disease [179]. Depletion of Tregs, a proposed strategy in cancer immunotherapy, was tested using cyclophosphamide (CY). Low-dose CY, which selectively depletes Tregs, decreased MM incidence, in contrast to high-dose CY, which was generally cytotoxic, and did not reduce MM incidence. On the other hand, the number and function of NK cells could be recovered, the production of IFN- $\gamma$ was enhanced, and DCs could continue their differentiation and become mature and ready for activation [179]. 
Th1-type cytokines invariant natural killer T (iNKT) cells have been shown important in initiating antitumor immune responses. Through the production of IFN- $\gamma$, iNKT cells can stimulate the activation of downstream effectors including $\mathrm{T}$ cells, NK cells, dendritic cells, and macrophages and increase NK and T cell proliferation and cytotoxicity through IL-2 production [180-183]. However, both quantitative and qualitative defects of iNKT cells in advanced MM hamper their antitumor effects. Song et al. developed a novel immunotherapeutic strategy directed at the activation and expansion of Th1-polarized iNKT cells from MM patients [184]. Functional iNKT cell lines were generated from MM patients with a-GalCer-pulsed DCs and further improved by lenalidomide. These results provide the preclinical feasibility and rationale for iNKT cell-mediated immunotherapy in MM [184].

\section{Monoclonal Antibodies in the Treatment of MM}

9.1. General Considerations. A wide range of antigens may ultimately be targeted in MM therapy, including those involved in cell survival, antiapoptotic pathways, cell-to-cell communication, angiogenesis, and interactions between MM cells and bone marrow stromal cells (BMSCs) and/or other cells in the BM microenvironment [26, 185]. These potential targets include signalling molecules, cell surface receptors and other cell surface proteins, plasma cell growth factors, and mediators for adhesion. Ideally, a useful target for mAb-based MM therapy should be expressed exclusively on the majority of the MM cells (or other target cells such as those involved in angiogenesis) [26]. The clinical efficiency of most therapeutic antibodies is based on their capacity to recruit and activate cytotoxic effector mechanisms of the innate immune system. This occurs either by engagement of activating Fc receptors expressed on NK cells or macrophages on the tumor cell surface leading to ADCC or by activating the complement cascade through tumor cell-bound antibodies (CDCC). Other possible mechanisms include interference with ligand binding (e.g., growth factor or G-protein coupled receptors) and the use of mAbs as targeted "carriers" of cytotoxic agents [4].

CD20. Clinical studies of rituximab therapy for MM have been disappointing, as only a few of the patients showed minimal response [186]. The failure of rituximab in this setting is potentially attributable to the small number of MM patients (estimated at 13-22\%) who express CD20 in primarily a low proportion of plasma cells. Another mechanism that may render MM refractory to rituximab is the possibility that MM cells express increased levels of complement-inhibiting proteins, thus reducing the effectiveness of CDC. In addition, FC-c receptor polymorphism may limit the effectiveness of ADCC as a killing mechanism. Finally, the use of rituximab for MM may induce a selective loss of the CD20 expression [186]. Although it is conceivable that rituximab may be useful for some carefully-selected MM patients, such as $\mathrm{t}(11$; 14) translocation patients, who exhibit relatively high CD20 expression [187], it is unlikely to be of value for the majority of cases.
CD40. CD40 is a transmembrane protein belonging to the TNF- $\alpha$ superfamily, normally expressed in the resting cell types, with the highest levels of expression found in B and DCs [188-190]. CD40 is expressed at high levels on the surface of MM cell lines and primary MM cells [191]. The binding of CD40 to its natural ligand determines its functional activation that, in turn, induces diverse biologic events including $\mathrm{MM}$-cell proliferation and migration via the $\mathrm{PI} 3 \mathrm{~K} / \mathrm{AKT} / \mathrm{-NF} \kappa \mathrm{B}$ signaling pathway. CD40 is also expressed by BMSCs, and upon activation it triggers the secretion of IL6 and VEGF [192-194]. Thus, inhibition of CD40-CD40L interaction could exert antimyeloma activity through the blockage of several critical pathways in MM or in BMSCs. Monoclonal antibodies developed against CD40 (SGN-40, CHIR-12.12) [195] have shown a modest cytotoxic activity against MM cell lines and primary MM cells when used as single agents for treatment [196]. The mechanisms of action rely on the inhibition of CD40-CD40L interaction and activation as well as on ADCC [197, 198]. Although earlier trials in NHL and MM were promising, a Phase II NHL trial comparing therapy with the anti-CD40 antibody SGN-40 with existing treatments alone was stopped because of lack of efficacy. Horton et al. described the characterization of $\mathrm{XmAbCD} 40$, a humanized anti-CD40 antibody with increased $\mathrm{F}_{\mathrm{C}} \gamma \mathrm{R}$ binding that facilitates highly enhanced ADCC against B-lymphoma, leukemia, and MM cell lines and against primary tumor cells from patients with CLL and plasma cell leukemia (PCL) [199]. XmAbCD40 shows nearly 2 orders of magnitude increased binding to Fc $\gamma$ RIIIa and 1 order of magnitude increased binding to Fc $\gamma$ RIIa. The increased affinity for Fc $\gamma$ RIIIa translated into dramatically increased NK cell-mediated ADCC. Results were consistent in several cell lines expressing different levels of CD40 antigen as well as in patient-derived primary tumors [199].

The observation that SGN-40-induced MM cell death is enhanced by lenalidomide [200] led to its evaluation in a Phase I study in combination with lenalidomide and dexamethasone in patients with relapsed or refractory MM; an overall response (OR) of 39\% (13/36) was seen, with some activity noted in patients receiving prior lenalidomide [201]. Phase I clinical trials of SGN-40 in combination with other agents are currently ongoing [202].

Lucatumumab is a fully human anti-CD40 MAb that inhibits MM cell growth in vitro, even when MM cells are cocultured with BMSCs. Animal studies have shown that the primary cytotoxic mechanism is ADCC [198]. However, a Phase I study of lucatumumab in patients with relapsed/ refractory MM was terminated because of minimal biological and clinical activity (NCT00231166).

CS1 (CD2 Subset 1, CRACC, SLAMF7, CD319, or 19A24). CS1 is a cell surface glycoprotein of the immunoglobulingene superfamily with high expression on the surface of MM cell lines and on plasma cells from MM patients [203]. It is not expressed on other normal tissues [203]. The role of CS1 is not well understood; however, there is evidence that it participates in promoting and supporting MM cell adhesion, tumor growth, and proliferation through interactions with 
bone marrow stromal cells mediated by c-maf pathway activation $[203,204]$.

A humanized mAb developed against CS1 elotuzumab (HuLuc63) has been proven to induce significant antimyeloma activity both in vitro and in vivo $[203,205]$. In vitro, the employment of bortezomib has been shown to increase HuLuc63-induced ADCC [206]. In vivo injection of the $\mathrm{mAb}$ significantly induced tumor regression in xenograft myeloma mouse models [203]. Based on these results, Phase I clinical trials are underway to evaluate the safety and toxicity of the HuLuc63 in myeloma patients [207]. Elotuzumab demonstrated acceptable toxicity but its antitumor activity was only modest: no responses were seen, although elotuzumab did induce stable disease (SD) in six of 19 patients [208]. Clinical studies of elotuzumab combined with either lenalidomide plus dexamethasone or with bortezomib were therefore initiated and are showing considerable promise. In a preliminary analysis of an ongoing phase I study of elotuzumab plus bortezomib, the ORR (partial pesponse (PR) or better) was $48 \%$ for 27 evaluable patients, and responses were achieved for several bortezomib-refractory patients. A clinical response was seen in 17/27 (63\%) patients. The response rate was lower among heavily pretreated patients $(>3$ prior therapies) and the median time to progression was 9-46 months [209]. In a preliminary analysis of an ongoing Phase Ib combination study with lenalidomide and dexamethasone, the ORR was $82 \%$ for all treated patients $(n=28), 96 \%$ for lenalidomide-naïve patients $(n=22)$, and $82 \%$ among patients who had been refractory to their most recent treatment $(n=11)$ [210]. In a Phase II study of the same combination, the ORR was $85 \%$ for evaluable patients (22/26), and the remaining four patients had SD; $31 \%$ achieved either a complete remission (CR) or very good partial response (VGPR) [211]. Elotuzumab is therefore the first $\mathrm{mAb}$ in combination with either bortezomib or lenalidomide and dexamethasone to demonstrate clinically meaningful efficacy in relapsed/refractory MM.

CD138 (syndecan-1). syndecan-1 is a member of the syndecan family, which includes cell-surface heparan sulfate proteoglycans involved in cell adhesion, maturation, and proliferation [212]. The high levels of heparan sulfate in the tumor microenvironment resulting from syndecan- 1 shedding also act as positive regulators that condition the microenvironment for robust tumor growth. This antigen is usually absent on haematopoietic cells; conversely it is frequently expressed on normal and myeloma plasma cells. When present at high levels in the serum, syndecan-1 is an independent indicator of poor prognosis [213-215]. Studies in animal models have shown that high levels of soluble syndecan-1 enhance both the growth and metastasis of tumors [216]. Syndecan-1 has been explored as a candidate antigen for antibody targeting of toxins to the tumor cell surface $[138,217-219]$.

CD74. CD74 expression has been demonstrated for more than $90 \%$ of B-cell malignancies [220] and for a high percentage of MM cases (around 80\%). To assess CD74 as a therapeutic target, an anti-CD74 mAb, LL1, has been developed [221]. LL1 activity hardly relied on ADCC and CDC mechanisms. This feature makes it feasible to use drug- and toxin-conjugated or radiolabelled forms of LL1 instead of unconjugated ones. hLL1-dox (IMMU-110), for example, is an immunoconjugate composed of doxorubicin conjugated to hLL1 IMMU-110 which has been evaluated in preclinical studies with non-Hodgkin's lymphomas and MM models, resulting in the achievement of an excellent therapeutic response [221, 222]. IMMU-110 appeared to be safe in a monkey model of MM [222]. IMMU-110 is being evaluated in a Phase 1/2 study (NCT00421525), and a Phase 2 study is currently ongoing (NCT01101594).

CD162. CD162 has been found to be constitutively expressed in indolent and aggressive plasma cell disorders, including MM, and in normal plasma cells [223]. The antiCD162 blocking mAb KPL1 has been recently tested in vitro. KPL1-mediated CD162 crosslinking was proven to induce death MM cells, in MM cell lines and in neoplastic cells purified from patients, mainly by activating the mitochondrial pathway of apoptosis [224]. KPL1 also mediated a significant induction of ADCC and to a lesser extent complementdependent cell lysis. Its action could be strongly enhanced by adding blocking $\mathrm{mAbs}$ against the complement regulatory proteins CD46, CD55, and CD59 highly expressed on the surface of MM cells [224].

CD66. CD66 proteins are expressed in a number of isoforms, which have a wide range of biologically important functions including cell adhesion, cellular migration, pathogen binding, and activation of signalling pathways. This was utilized in recent Phase I and II clinical trials [225, 226] for targeted delivery of radiotherapy to the BM as a part of the conditioning regimen for transplantation in acute leukemias and MM. The expression of CD66a but no other CD66 isoforms on two human myeloma cell lines (U266 and ARH77) and on plasma cells from patients with MM [227] may help in the optimization of future radioimmunotherapeutic strategies by supporting the use of a monoclonal CD66a antibody for targeted radiotherapy in patients with MM [227].

Beta2-Microglobulin ( $\beta 2 \mathrm{M})$. $\beta 2 \mathrm{M}$ is a nonglycosylated polypeptide, which is a part of the MHC class I molecule on the surface of nucleated cells [228]. $\beta 2 \mathrm{M}$ is normally found in body fluids, but elevated serum levels are present in hematological malignancies [229], including MM [230], and correlate with a poor prognosis. The mAbs against $\beta 2 \mathrm{M}$ have a remarkably strong apoptotic effect on myeloma cells [231]. The anti-MM activity of this antibody was confirmed by in vivo in a MM xenograft mouse model experiment which demonstrated selective effect on tumor cells without damaging BM hematopoietic cells of implanted human bone or murine organs expressing $\beta 2 \mathrm{M} / \mathrm{HLA}-\mathrm{A} 2$ molecules [231, 232]. Therefore, such mAbs offer the potential for a therapeutic approach to hematological malignancies [233].

CD38. Under normal conditions, CD38 is expressed at relatively low levels on lymphoid and myeloid cells and in some 
tissues of non-hematopoietic origin [234]. In the past, several Abs to human CD38 have been generated. These Abs induce killing of neoplastic B cell lines $[235,236]$. The relatively high expression of CD38 on all malignant cells in MM [237, 238] in combination with its role in cell signaling suggests CD38 as a potential therapeutic $\mathrm{Ab}$ target for the treatment of MM. Two CD38 mAbs are currently in clinical development: a humanized mAb (SAR650984) and a human mAb (daratumumab) [239]. Daratumumab was found to effectively kill MM tumor cells by ADCC and CDC. It was active at low concentrations in a SCID mouse xenograft tumor model. Daratumumab is currently in a Phase I/II safety and dose finding study for the treatment of MM (NCT00574288). Results of this preliminary study are awaited with interest, with early reports suggesting favourable tolerability and disease stabilization for some patients [28]. In a series of experiments using a CD38+ MM cell line, purified MM cells, and full BM mononuclear cells (BM-MNC) of MM patients containing 2-50\% malignant plasma cells, van der Veer et al. demonstrated that lenalidomide significantly improves daratumumab-dependent lysis of MM cells [240].

PD1. Accumulating experimental evidence indicates that PD1 is a coinhibitor and primarily involved in the regulation of T cell and NK-cell responses. Anticancer immunotherapy based on antibodies directed against the B7 family of receptors, particularly the B7 homologue 1 (B7-H1)-programmed death 1 (PD1) system, suggests a promising novel approach for promoting immune responses against cancer as well as breaking up tumor resistance and dormancy. CT-011 is a humanized IgG1 mAb that modulates the immune response. Interaction of CT-011 with PD-1 leads to stimulation of the NK-cell activity and to extended survival of effector/memory $\mathrm{T}$ cells, culminating in the enhancement of antitumor immune response and the generation of tumor-specific memory cells [241]. CT-011 was recently administered to patients with various hematologic malignancies, including MM at an advanced stage of their disease and following chemotherapy and/or stem cell transplantation [242]. Clinical benefit was observed for $33 \%$ of the patients with one CR [242]. Currently a new clinical study recruits patients to evaluate the efficacy and safety of CT-011 following autologous transplantation and a Phase II study to determine if cellular immunity is induced by treatment with CT-011 and DC/myeloma fusion cells in conjunction with stem cell transplantation (NCT01067287).

IL-6. IL-6 has been recognized as a key cytokine in the development and progression of MM, exerting antiapoptotic activity and multiple additional effects within the BM. IL-6 is produced predominantly by BMSCs and is upregulated by multiple cytokines [185]. Both IL-6 and its receptor, IL-6R, are potential targets for $\mathrm{mAb}$-based intervention. A chimseric anti-IL-6 mAb, siltuximab (CNTO 328), enhances dexamethasone-induced cytotoxicity in MM cell lines, and in MM cells from patients refractory to dexamethasone therapy, it also enhances the cytotoxicity of the bortezomib plus dexamethasone combination [243]. Siltuximab is currently being evaluated in MM in multiple single-arm and randomized Phase II studies, either alone or in combination with bortezomib (NCT01219010, NCT00402181, NCT00911859, NCT00412321, NCT00401843). Preliminary results in combination with bortezomib have shown promise, with a $57 \%$ objective response rate (ORR), although grade $3+$ haematological toxicities were somewhat common [244]. A Phase III study of siltuximab or placebo in combination with bortezomib and dexamethasone is underway (NCT01266811).

A murine anti-IL-6 mAb, BE- 8 , has been evaluated in combination with dexamethasone and high-dose melphalan as a conditioning regimen for ASCT. The combination induced a response in 13 of 16 patients $(81 \%)$ and a CR in 6 patients $(37.5 \%)$. The overall response (OR) was similar to historical controls by the same group of high-dose melphalan; however, the CR rate appeared to be higher and was correlated with IL-6 neutralization [245]. In a subsequent prospective, multicentre randomized trial by the same group, the addition of BE- 8 to the melphalan plus dexamethasone conditioning regimen showed no improvement in response or survival rates for patients with high-risk MM [246].

Tocilizumab is a humanized anti-IL-6 mAb currently approved for rheumatoid arthritis in several countries, and for the Castleman disease in Japan, has demonstrated efficacy in a murine MM model [247] and is currently being evaluated clinically in MM. Another anti-IL-6 mAb, 1339, has demonstrated activity on MM cell lines (cocultured with BMSCs) in vitro and in murine xenograft MM models; it is not yet being evaluated clinically [248].

VEGF. VEGF is a key cytokine that promotes angiogenesis in a variety of tumour types. Bevacizumab, a humanized antiVEGF mAb, is currently indicated for treatment of colorectal cancer. In a Phase II study in patients with relapsed/refractory MM, seven out of 10 patients responded partial response (PR) to bevacizumab in combination with low-dose dexamethasone and lenalidomide [249]. An additional phase II study of the same combination reported similar results in a larger patient population (OR 19/27, 70\%) [250], noting that this response rate was not significantly different from that seen in the pivotal Phase III trial of lenalidomide plus dexamethasone (61\%) [251]. An additional Phase II study of this combination is currently recruiting patients (NCT00410605), and the drug is also being evaluated in combination with bortezomib (NCT00464178, NCT00473590).

GM-2. GM-2 is a ganglioside expressed on MM cells. A humanized anti-GM-2 mAb, BIW-8962, has demonstrated in vitro killing of $\mathrm{MM}$ cell lines and in vivo effectiveness in mouse xenograft models, with ADCC and CDC the most prominent cytotoxic mechanisms [252]. BIW-8962 is being evaluated as monotherapy in a Phase I/II study for patients with relapsed/refractory MM (NCT00775502).

CD200. CD200 is a highly conserved transmembrane glycoprotein expressed on a wide range of cell types; however, expression of the receptor for CD200 (CD200R1) is apparently limited to APC of myeloid lineage and certain T cell 
populations and is thought to deliver inhibitory signals. The expression of the CD200 gene by MM cells has been found to be a predictor of poor prognosis in patients with MM [253]. ALXN6000 is a humanized anti-CD200 mAb that is currently being evaluated in a Phase $1 / 2$ study in patients with $\mathrm{MM}$ or B-cell CLL (NCT00648739), with results expected in the near future.

Killer Cell Immunoglobulin-Like Receptors (KIRs). KIRs are receptors expressed on natural killer (NK) cells and a subset of $\mathrm{T}$ cells and function as key regulators of NK cell activity [254]. IPH 2101 (anti-KIR) is a fully human monoclonal antibody blocking interaction between KIR inhibitory receptors on NK cells with their ligands. By blocking these receptors, it facilitates activation of NK cells and, potentially, destruction of tumor cells by the latter. Several studies are currently underway in smoldering and firstrelapse MM (NCT01222286, NCT01217203, NCT00999830, NCT01248455) and safety and tolerability results are expected later in 2011 for a Phase 1 study in relapsed or refractory MM (NCT00552396).

\section{Monoclonal Antibodies and Highly Cytotoxic Compounds}

The immune system of MM patients is impaired by the disease or by cancer treatments. Along with efforts to develop functional antibodies, substantial efforts are underway to develop therapies using antibodies conjugated with potent cytotoxic agents. A variety of highly cytotoxic compounds are being evaluated for antibody-based delivery, including calicheamicin, doxorubicin, taxanes, maytansinoids, dolastatins, and CC-1065 analogs [255-258]. Immunoconjugate IMGN901 (BB-10901; huN901-DM1) is composed of a humanized monoclonal antibody that binds with high affinity to CD56 conjugated with the cytotoxic maytansinoid DM1 through a disulfide linkage [258]. Upon binding to a target tumor cell, the antibody-maytansinoid conjugate is internalized by natural processes, where the conjugate is metabolized and active maytansinoid metabolites are released [259]. Within the hematopoietic compartment, while CD56 expression is normally restricted to NK cells and a subset of T lymphocytes $[260,261]$ and is absent from normal plasma cells [262], it is strongly expressed on MM cells in the majority of MM patients [263-266]. Tassone et al. demonstrated the activity of IMGN901 against CD56+ MM cells both in vitro and in vivo. Target-dependent cytotoxicity was shown in cocultures of CD56+ and CD56- cells [263]. Treatment with IMGN901 in a human MM tumor xenograft model in immunocompromised mice showed that the immunoconjugate was effective in both a minimal and bulky disease setting. The clinical evaluation of IMGN901 was initiated with a Phase I study in patients with relapsed or relapsed/refractory MM who failed at least one prior therapy and have CD56+ MM (NCT00346255) [258]. Additive to synergistic activity has been observed in combinations of IMGN901 with lenalidomide, bortezomib, or melphalan in MM xenograft models $[267,268]$.
BT062 is a chimeric mAb conjugated to maytansinoid derivatives that demonstrates in vitro cytotoxicity and inhibition of MM cells in mouse xenograft models, apparently via apoptotic mechanisms; BT062 also inhibits the adherence of MM cells to BMSCs and abrogates the protective effects exerted by growth factors and BMSCs on MM cells [269]. The local release of potent maytansinoid moieties from target cells and uptake into nearby nontarget cells is the proposed mechanism for this activity [269] and may have an important impact on BT062 efficacy through eradication of tumor cells that heterogeneously express CD138 or disruption of the tumor microenvironment by elimination of tumor stromal cells. A Phase I dose finding study of BT062 for patients with relapsed/refractory MM is underway (NCT00723359), and an additional Phase I/IIa study is ongoing but not recruiting patients with advanced MM (NCT01001442).

\section{Immunotherapy Approaches Targeting Microenvironment and the Neoplastic Niche of MM}

The BM microenvironment encompasses a wide spectrum of cell types and extracellular matrix proteins, including fibronectin, collagen, laminin, and osteopontin. Multistep genetic and microenvironmental changes lead to the transformation of plasma cells into a malignant neoplasm. Genetic abnormalities alter the expression of adhesion molecules on myeloma cells, as well as responses to growth stimuli in the microenvironment [270].

A cardinal clinical feature of $\mathrm{MM}$ is the presence of osteolytic bone lesions. Myeloma cells disrupt the delicate balance between bone formation and bone resorption [271, 272]. The inhibition of the Wnt pathway suppresses osteoblasts, whereas the amplification of the RANK pathway and the action of macrophage inflammatory protein $1 \alpha(\mathrm{MIP} 1 \alpha)$ activate osteoclasts [271]. The induction of proangiogenic molecules (e.g., VEGF) enhances the microvascular density of bone marrow and accounts for the abnormal structure of myeloma tumor vessels [273]. Various clinical observations [274] and experimental studies $[275,276]$ have linked the level of the MM bone disease with the disease burden. Tumor cells and stromal cells interact via adhesion molecules and cytokine networks to simultaneously promote tumor cell survival, drug resistance, angiogenesis, and disordered bone metabolism. In addition, the amounts of several of immunologically active compounds increase including TGFb, IL-10, IL-6, VEGF, Fas ligand, MUC-1, cyclooxygenase (COX)-2, and related prostanoids and metalloproteinases [277].

In addition to therapy directed at MM cells and tumour promoting interactions, some efforts have been devoted to $\mathrm{mAb}$ therapy directed against the development of end-organ complications; to date, these efforts have been restricted to the suppression of myeloma-related bone disease.

Angiogenesis is considered a hallmark of MM progression. As indicated before in patients affected by MM syndecan-1, a heparan sulphate proteoglycan is overexpressed by myeloma cells in the BM and peripheral blood [212]. 
The high levels of heparan sulfate in the tumor microenvironment resulting from syndecan-1 shedding also act as positive regulators that condition the microenvironment for robust tumor growth. For example, heparan sulfate binds to and promotes the activity of important angiogenic growth factors such as fibroblast growth factor-2 (FGF-2) and VEGF $[278,279]$. Recent research has shown that syndecan-1 could also be involved in the modulation of the growth and survival of endothelial cells (ECs) within the BM microenvironment [280]. Enzymatic remodeling of heparan sulfate proteoglycan structure and function within the tumor microenvironment is emerging as an important mechanism for dynamic regulation of tumor growth [281]. There are three forms of enzymatic remodeling of heparan sulfate proteoglycans that are known to occur in myeloma, and other tumors, sulfatases, sheddases, and heparanase, which are active within the tumor microenvironment, point out the importance of regulated remodeling of heparan sulfate proteoglycans [216, 281-284]. Certain heparinase gene SNPs may contribute to basal heparanase gene expression. Alterations in this gene are an important determinant in the pathogenesis of ALL, AML, and MM [285]. Dynamic regulation of heparan sulfate structure by sulfate 6-O-endosulfatases (Sulfs) present within the tumor microenvironment can have a dramatic impact on the growth and progression of malignant cells in vivo [283].

The high serum level of shed syndecan-1 has been associated with an unfavourable prognosis $[213,215]$.

Hence, the designing of novel agents that regulate the remodeling processes of heparan sulfate proteoglycans or inhibiting of VEGF as discussed previously represents a new opportunity for therapeutic control of malignant cell growth. Huang and zhan investigated the effect of VEGF antisense (AS) RNA on proliferation and apoptosis in myeloma cell line U266 as well as on angiogenesis in endothelial cell ECV304 and to explore the feasibility of gene therapy for MM using VEGF antisense RNA [286]. VEGF121 cDNA was inserted into a multiple clone site of eukaryotic expression vector pIRES2-EGFP to construct the recombinant plasmid AS-VEGF. The recombinant plasmid was transfected into a human myeloma cell line U266. Expression of VEGF mRNA and protein decreased more significantly in U266 cells transfected by AS-VEGF than that in control group. VEGF antisense RNA can inhibit the expression of VEGF gene in U266 cells, thereby inhibits the proliferation of U266 cells, increases the apoptosis of U266 cells, and inhibits angiogenesis in vitro [286].

Another novel therapeutic concept related to the microenvironment is the introduction of antiadhesion strategies. Podar et al. evaluated the therapeutic potential of the new-inclass molecule-selective adhesion molecule (SAM) inhibitor Natalizumab, a recombinant humanized IgG4 monoclonal antibody, which binds integrin- $\alpha 4$, in MM [287]. Natalizumab, but not a control antibody, inhibited adhesion of MM cells to non cellular and cellular components of the microenvironment as well as disrupted the binding of already adherent MM cells. Moreover, natalizumab also blocked VEGFand insulin-like growth factor 1 (IGF-1)-induced signalling sequelae triggering $\mathrm{MM}$ cell migration. Natalizumab not only blocked tumour cell adhesion but also chemosensitized
MM cells to bortezomib, in an in vitro therapeutically representative human MM-stroma cell coculture system model.

Some MM cells that harbor oncogenic translocations remain dependent on the stroma for their survival, while others acquire additional mutations which affect NF- $\kappa$ B pathways and remove their reliance on the bone marrow microenvironment [288]. Mutations affecting the activation of $\mathrm{NF}-\kappa \mathrm{B}$-inducing kinase (NIK) have been identified in MM samples and cell lines, suggesting that NIK could be an important target for therapy of MM. The majority of MM samples display high constitutive NF- $\kappa \mathrm{B}$ activity and up to $20 \%$ results from mutations in NF- $\kappa \mathrm{B}$ signaling components, including NIK. Inhibition of NIK may be an effective therapeutic for some MM cases. There are several new agents under investigation that induce apoptosis of myeloma cells. Celastrol is a quinone methide triterpene derived from the medicinal plant Tripterygium wilfordii, acts by NF- $\kappa \mathrm{B}$ pathway, and induces cell cycle arrest at the G1 phase followed by apoptosis in human myeloma cell line U266 cells [289]. Several studies have showed that miRNAs play important roles in the regulation of cell proliferation, differentiation, and apoptosis [290, 291]. The deregulation of miRNAs expression contributes to tumorogenesis by modulating oncogenic and tumor suppressor signaling pathways.

\section{Receptor Activator of Nuclear Factor Kappa-B Ligand (RANKL)}

RANKL promotes bone loss in osteoporosis and contributes to the development of bone lesions in MM. The inhibition of RANKL may directly impact myeloma cells that express RANK and have a therapeutic role in the treatment of MM. The fully human anti-RANKL mAb, denosumab, has demonstrated some efficacy in a Phase II study of patients with plateau-phase or relapsed MM, including suppression of the bone turnover marker serum C-terminal telopeptide of type 1 collagen (sCTx) [292]. Denosumab is currently being compared with zoledronic acid (the standard of care for prevention of bone disease in several cancers) in patients with advanced cancers or MM in a randomized Phase III trial (NCT00330759); results in the MM cohort have thus far been mixed although positive in other cancers; future trials are planned in MM to better define its role.

\section{Dickkopf-Related Protein 1 (DKK1)}

The canonical Wnt pathway plays an important role in controlling proliferation, differentiation, and survival of OBs. In MM, high serum DKK1 levels were correlated with focal bone lesions [293]. The DKK1 produced by MM cells can inhibit the differentiation of OB precursor cells [293] and bone formation in vitro [294] through a DKK1-mediated attenuation of Wnt3a-induced stabilization of $\beta$-catenin [295]. These findings confirm DKK1 as an important regulator of bone formation in the bone microenvironment. The broad expression in myeloma but highly restricted expression in normal tissues, together with its functional roles as an $\mathrm{OB}$ formation inhibitor and a potential myeloma growth enhancer, make DKK1 an ideal and universal target for 
immunotherapy. DKK1 (peptide)-specific CTLs can effectively lyse primary myeloma cells in vitro [296]. A fully human anti-DKK1 mAb, BHQ880, has demonstrated improvement in the bone parameters in murine models and also appears to have direct effects on the MM cell growth, possibly via interactions with the BMSCs and the IL-6-related pathways [297, 298]. BHQ880 is being evaluated in combination with zoledronic acid in a Phase 2 study in patients with relapsed/refractory MM (NCT00741377), and studies in early MM (i.e., smoldering MM) are also underway.

\section{Biphosphonates-Activated T Cell-Based Immunotherapy}

Aminobiphosphonates, such as pamidronate and zoledronate, were originally developed for osteoporosis but are increasingly used for cancer therapy. They have been shown to activate $\mathrm{V} \gamma 9 \mathrm{~V} \delta 2 \mathrm{~T}$ cells, and the activated cells were functionally characterized in vitro and in vivo [299-302]. In vivo study, evaluated administration of low-dose IL-2 in combination with pamidronate to patients with low-grade nonHodgkin lymphoma or MM, showed that only patients with significant in vivo proliferation of $\gamma \delta \mathrm{T}$ cells responded to treatment [303]. Abe et al. [304] in a clinical phase I study evaluated the clinical and immunological effects of zoledronate-activated $\mathrm{V} \gamma 9 \mathrm{~V} \delta 2 \mathrm{~T}$ lymphocyte-activated killer (LAK). Six patients with MM received no antimyeloma therapy in the preceding 2 months and during the study period received four biweekly intravenous infusions of zoledronateactivated $\mathrm{V} \gamma 9 \mathrm{~V} \delta 2 \mathrm{~T}$ LAK cells generated from the culture of PBMCs in the presence of zoledronate and IL-2. This showed that administration of zoledronate-activated $\mathrm{V} \gamma 9 \mathrm{~V} \delta 2 \mathrm{~T}$ LAK cells, a safe and immunotherapy for MM patients, is promising, and zoledronate-activated $\mathrm{V} \gamma 9 \mathrm{~V} \delta 2 \mathrm{~T}$ cells warrant further clinical investigations.

\section{Changes in Mesenchymal Stromal Cells from Multiple Myeloma Patients}

BM-derived mesenchymal stromal cells (MSCs) are precursors of OBs and differentiate preferentially into bone-forming cells both in vitro and in vivo. MM cells were suggested to target MSCs thereby diverting their functions to serve the MM cells. This idea led to studies of the functions of MSCs derived from MM patients (MM-derived MSCs) compared to those of healthy individuals; it was suggested that MSCs from myeloma patients exhibit defective functions [68-70]: MM-derived MSCs were reported to exhibit decreased colony-forming unit number [70], growth impairment [70], reduced osteogenic differentiation [68], and increased IL-6 secretion $[68,70]$. However, these observations were not reproducible in all reports [68-70]. Some authors focused on toll-like receptor (TLR) ligands and on the cytokine epidermal growth factor (EGF). They [305-310] have shown that TLR activation modulates MSC proliferation, migration, and differentiation. However, MM-derived MSCs exhibited reduced activation of extracellular signal-regulated kinases (ERK1/2) and may therefore represent a general property of this signaling pathway in MM-derived MSCs. These altered responses persisted in MSCs from MM patients following extended culture and passaging in vitro, indicating that these cells are permanently modified. Activation of MAPK pathway contributes to drug resistance, growth, and survival [311]. MSCs derived from MM patients have been shown to exhibit different gene expression profiles when compared to control MSCs $[68,312]$. Furthermore, these MSCs have been suggested to be genomically altered [313]. MM-derived MSCs are intrinsically and permanently modified. The treatment of the disease may therefore require not only the elimination of the tumor cells but concomitantly treatment or replacement of stromal elements.

\section{Immunotherapy after Autologous Stem Cell Transplantation for MM}

A major area of investigation is to develop strategies to elicit myeloma-specific immune responses that will selectively eliminate malignant cells and eradicate residual disease following ASCT. High-dose melphalan induces severe and persistent immunosuppression characterized by a delayed recovery of CD4 T cells that remain below normal counts for months to years after ASCT $[314,315]$, a restricted T cell repertoire [316], and impaired $\mathrm{T}$ cell functions including an increased susceptibility to apoptosis [317], a reduced proliferation intensity upon stimulation with mitogens or defined antigens and a default in Th1 cytokine production that lasts at least one year after ASCT in patients with MM [318, 319]. The B-cell immune response is also altered after ASCT since levels of plasma antibodies after one recall vaccination are below those found in healthy donors [315]. T cell functions are impaired after transplantation in patients with MM despite a recovery of normal numbers of $\mathrm{T}$ lymphocytes [317319]. In theory, the posttransplantation phase should be highly amenable to the application of immunotherapy because of a lower tumor burden. However, after high-dose therapy, the immune system is characterized by immune cell depletion and impaired function that may last for years [314]. The therapeutic induction of rapid lymphocyte recovery consistents that unmanipulated lymphocyte levels in patients with myeloma correlate to event-free survival (EFS) [320-323]. Rapoport et al. have developed a strategy for inducing an effective antitumor immune response during the posttransplantation period and to control or eliminate residual disease [324]. The authors hypothesized that enhanced numeric and functional recovery of $\mathrm{T}$ cells might provide a platform for posttransplantation tumor vaccine immunotherapy. The autologous $\mathrm{T}$ cells were costimulated with paramagnetic beads that deliver CD3 and CD28 signals designed to reverse T cell anergy [325-328]. Patients with myeloma received costimulated autologous $\mathrm{T}$ cells after autotransplantation, along with immunizations with a 7-valent pneumococcal conjugate vaccine (PCV; Prevnar; Wyeth) $[324,329]$. In addition, patients who were positive for human leukocyte antigen A2 (HLA-A2) received a multipeptide tumor antigen vaccine that was based on peptides derived from human telomerase reverse transcriptase (hTERT) and 
survivin, 2 "universal" tumor antigens that are often overexpressed in myeloma and may have prognostic relevance [330-332]. In this study adoptive transfer of vaccine-primed and costimulated autologous $\mathrm{T}$ cells generates a rapid and schedule-dependent recovery of the cellular and humoral immune system in patients with myeloma. Immune responses to a cancer vaccine occur in a substantial proportion of patients early after autotransplantation [324]. Some studies have shown high IL-6 plasma levels after ASCT $[333,334]$. Condomines et al. showed that IL-7 and IL-15 plasma levels increase and peak at a median day 8 after HDM and ASCT in patients with MM [335], supporting results found in mice by Restifo and coworkers [336]. Increasing data support the idea that the early period following-lymphodepletion is propitious to promote amplification of adoptively transferred $\mathrm{T}$ cells and to enhance their functions. Several studies in mice and humans showed that homeostatic expansion is associated with faster and more efficient immune response and that immunization with tumor antigens during lymphopenia generates CD8 T cells with enhanced antitumor capacities [337-340]. IL-7, produced by stromal cells, is required for homeostatic expansion of naïve and memory CD4 and CD8 T cells and is critical for their survival [341]. IL-15 drives antigen-independent homeostatic memory CD8 $+\alpha \beta$ T cell proliferation [341, 342]. IL-7 and IL-15 are also required for $\gamma \delta \mathrm{T}$ cell homeostatic expansion [343]. The $\gamma 9 \delta 2 \mathrm{~T}$ cells exert antimyeloma-specific cytotoxicity, can be expanded 100-fold with IL-2 and biphosphonate ex vivo [344], and are present in mobilized autografts [345]. These $\gamma 9 \delta 2 \mathrm{~T}$ cells could be expanded ex vivo and then grafted after ASCT. CD8 T cells recognizing several myeloma antigens as MUC-1 [346], cancer-testis antigens [124, 126, 127], or IgG epitopes [347], detected in peripheral blood of patients, may also be present in HSC harvests. Once stimulated ex vivo with antigen-pulsed DCs [348], these antimyeloma cell CD8+ T cells are able to kill myeloma cells.

\section{Immunotherapy after Allogeneic SCT}

Allogeneic transplantation results in long-term disease-free survival for a subset of patients with MM. The unique efficacy of allogeneic transplantation is due to the graft-versusdisease effect that is mediated by alloreactive donor $\mathrm{T}$ cells $[5,349,350]$.

Compared with autologous transplantation, allogeneic transplantation results in lower rates of disease relapse and higher rates of molecular remission [5, 351-353]. Standard myeloablative alloSCT for myeloma is associated with a rather high treatment-related mortality. One approach to reduce transplant-related mortality is the use of reduced-intensity conditioning regimens [354] in which the primary antimyeloma cytoreductive agent is the donor lymphocytes contained in the graft or administered as part of DLI at a subsequent time point. The CR rate of allogeneic stem cell transplantation after standard myeloablative and dose-reduced conditioning ranged between $27 \%$ and $81 \%$ [354358]. The ability of donor lymphocyte infusions (DLIs) to eradicate posttransplant disease relapse demonstrates the potency of the graft-versus-myeloma effect [37]. Because only those patients who achieved molecular remission have a high probability of long-term freedom from disease and cure [359], a higher number of CRs, especially molecular CRs, must be reached. For upgrading non-CR into CR may be used DLI as adoptive immunotherapy after allogeneic stem cell transplantation. In most reports on DLI in myeloma, DLI was given for relapse [360-362] and only a few reported on prophylactic DLI $[363,364]$. Most studies till date have used relatively high $\mathrm{T}$ cell doses, resulting in a high rate of aGvHD up to $55 \%$. DLI given after reduced-intensity conditioning in a dose-escalating manner resulted in less acute and chronic GVHD [363]. Ayuk et al. thus considered it important to find DLI doses that may induce a graft-versus-myeloma effect without GvHD [362]. Their data show that it is possible to achieve remission in myeloma patients who have relapsed, persistent, or progressive disease following RIC allografting with much lower $\mathrm{T}$ cell numbers with relatively low starting doses $\left(1.010^{6} \mathrm{CD}^{+} / \mathrm{kg} \mathrm{BW}\right.$ for unrelated grafts and $4.710^{6}$ $\mathrm{CD}^{+} / \mathrm{kg} \mathrm{BW}$ for sibling grafts). The incidence and severity of aGvHD and cGvHD were relatively low [362]. Kroger et al. investigated the effect of DLI alone or in combination with sthalidomide, bortezomib, and lenalidomide in patients with MM who achieved only partial remission or very good partial remission after allogeneic stem cell transplantation [365]. Fifty-nine percent of patients achieved CR, and this CR resulted in significantly improved progression-free survival at 5 years ( $58 \%$ versus $35 \%$ ). CR by flow cytometry could be achieved in $63 \%$, and this resulted in an even more favorable event-free survival at 5 years (74\% versus 15\%) [365].

\section{Combined Donor Vaccination and Allogeneic Stem-Cell Transplantation}

A special aspect of active immunotherapy in MM is the combination of alloSCT with the induction of myeloma-specific immunity in the donor's immune system. The donor immune system is presumably naive for the patient's myeloma idiotype and therefore not tolerized or anergic. Therefore, induction of tumor-specific immunity in donors of haematopoietic stem cells for myeloma patients by idiotype immunization, followed by adoptive transfer of specific immune cells into the transplanted patient, may render allogeneic SCT from a nonspecific form of active immunotherapy into a tumor-specific therapy. In the 38C13 mouse lymphoma model, mice receiving marrow from a donor immunized with 38C13 idiotype had a statistically significant survival advantage after a lethal challenge with 38C13 lymphoma cells compared to animals transplanted with control marrow [366]. When preimmunized marrow transplantation was combined with a subsequent booster immunization, even tumor-bearing mice could evidently be cured of their disease. The protective effect was mediated by donor-derived T cells.

More recently, results from a formal clinical trial of donor idiotype immunization were reported. Five patients and their related donors received three subcutaneous vaccinations with idiotype (coupled to KLH at the 1st vaccination) and GM-CSF prior to alloSCT. All donors developed cellular and humoral anti-idiotype immune responses. After bone 
marrow transplantation, the three patients who survived longer than 30 days received 3 booster vaccinations with KLH-coupled idiotype and GM-CSF. Remarkably, these patients survived without evidence for disease recurrence for 5.5 to more than 8 years, and all had evidence for [367] idiotype-specific immunity after alloSCT.

One recipient suffered from chronic GvHD and was on chronic steroid therapy, while the other 2 recipients and all of the donors were medically well, without any significant complications.

In order to avoid immunization of the healthy donor, attempts have been made to generate myeloma idiotype-specific donor immunity through in vitro stimulation of donor $\mathrm{T}$ cells with monocyte-derived, idiotype-presenting DC [368]. Implementation of this approach would permit to extend the principle of transfer of tumour-specific immunity to the vast pool of unrelated stem cell donors for alloSCT.

\section{Conclusions}

MM continues to be an incurable disease with fatal outcome for the majority of patients at advanced stages. Therefore, exploration of novel therapeutic modalities should be pursued.

Immunotherapy seems promising and may prove effective in eradicating the malignant stem cell pool that is nonproliferating and generally resistant to chemotherapy.

Various clinical immunotherapy treatment strategies have been tested. Most of these strategies have focused on targeting idiotype-specific immunity. Idiotype-based vaccines have been shown in preclinical tests to induce or enhance idiotype-specific immunity. But clinical response is rare, occurring only in a minority of treated patients, suggesting that the effect is too weak to cause significant tumor destruction. Ideally, a tumor-specific immunotherapy should induce or expand only the beneficial immune responses mediated by CTLs (Th1 and Tc1 subsets) that have sufficient cytotoxic effects toward tumor cells but not normal cells. Further studies are warranted so to better understand the immune regulation mechanism in MM.

TSAs continue to be identified in myeloma, and a systematic assessment and comparisons to identify the most promising candidates for clinical trials, are necessary. Vaccination with $\mathrm{DC} /$ tumor fusions induces antitumor immunity in a majority of the patients; however, responses are transient and not always associated with clinical benefit. One potential limiting factor is the regulatory $\mathrm{T}$ cells. It is necessary to develop ways to promote the expansion and increase the amount of functionally competent tumor-reactive T cells and to limit the influence of regulatory $\mathrm{T}$ cells in order to improve the efficacy of the DC/MM fusion vaccine. One approach is vaccination in conjunction with ASCT which facilitates vaccine response by inducing a minimal disease state and limiting the inhibitory influence of the myeloma cells. In preclinical models, stem cell transplantation results in the in vivo depletion of regulatory $\mathrm{T}$ cells, transient loss of tumor mediated tolerance, and enhanced capacity to respond to tumor vaccines $[167,168]$. Exposure to lenalidomide increased cytotoxic $\mathrm{T}$ lymphocyte-mediated lysis autologous tumor targets indicating of the potential of cellular immunotherapy in conjunction with lenalidomide including its use as part in the DC/myeloma fusion vaccine [169].

Functionally potent DCs can be generated by stimulation with NK cells and may provide an effective source of DCbased immunotherapy in MM [174]. Modulation of inhibitory and activating NK receptor ligands on tumor cells represents a promising therapeutic approach against MM.

Perhaps the most interesting field for active immunotherapy in myeloma lies in the combination with allogeneic stem cell transplantation. This setting offers the advantage of an immune system that is unaffected by potential negative influences exerted by the tumor on the immune system. Transfer of tumor antigen-specific immunity from the donor to the myeloma patient may help to enhance the immunological efficacy of allogeneic SCT and to separate graft-versus-myeloma from graft-versus-host activity. The most crucial question to develop this concept further is whether the donor has to be immunized personally or whether efficacious, specific antitumor immunity can be induced ex vivo or in the transplanted patient.

MM exhibits a number of potentially valuable targets for $\mathrm{mAb}$ therapy that await further investigation in clinical studies. As has been the case with other cancers, mAbs, when employed as monotherapy in MM, have generally not produced impressive levels of response with respect to either response rates or extent of response in individual patients. However, preclinical results in $\mathrm{MM}$ cell lines and murine explant models and preliminary clinical results in patients with relapsed/refractory MM suggest that mAbs are likely to act synergistically with traditional therapies (dexamethasone), immune modulators (thalidomide, lenalidomide), and other novel therapies (such as the first-in-class proteasome inhibitor bortezomib); in addition, mAbs have shown the ability to overcome resistance to these therapies. These observations suggest that future work may be most productively directed at the rational development of multiagent therapies incorporating specific mAbs on the basis of clinical trial results and, possibly, on the identification of patientspecific MM disease factors. Indeed, many of the molecules composing the surface profile of plasma cells, such as CD38, CD138, CD162, and CD49d, are involved in the adhesive dynamics regulating the crosstalk between MM cells and the BM stromal environment. The search for new treatment strategies to improve outcomes for MM patients has led to the development of novel antibody-based therapies currently undergoing clinical evaluation.

Major progress in understanding interactions between the immune system and malignant cells will strongly augment the design of clinically more efficient study protocols in MM. Multiple different approaches are currently evaluated in clinical trials.

\section{Acknowledgments}

The authors wish to thank the Naor family for their support memorizing their dear son-in-law, Mr. Guy Weinstock, with the Guy Weinstock Multiple Myeloma Foundation, 
which supports research in the field of MM at the Division of Hematology at the Chaim Sheba Medical Center (Tel Hashomer, Israel) and the Jacqueline Seroussi Grant Award (A. Nagler).

\section{References}

[1] M. S. Raab, K. Podar, I. Breitkreutz, P. G. Richardson, and K. C. Anderson, "Multiple myeloma," The Lancet, vol. 374, no. 9686, pp. 324-339, 2009.

[2] K. Podar, Y. T. Tai, T. Hideshima, S. Vallet, P. G. Richardson, and K. C. Anderson, "Emerging therapies for multiple myeloma," Expert Opinion on Emerging Drugs, vol. 14, no. 1, pp. 99-127, 2009.

[3] J. A. Child, G. J. Morgan, F. E. Davies et al., "Highdose chemotherapy with hematopoietic stem-cell rescue for multiple myeloma," The New England Journal of Medicine, vol. 348, no. 19, pp. 1875-1883, 2003.

[4] L. M. Weiner, R. Surana, and S. Wang, "Monoclonal antibodies: versatile platforms for cancer immunotherapy," Nature Reviews Immunology, vol. 10, no. 5, pp. 317-327, 2010.

[5] C. Crawley, S. Iacobelli, B. Björkstrand, J. F. Apperley, D. Niederwieser, and G. Gahrton, "Reduced-intensity conditioning for myeloma: lower nonrelapse mortality but higher relapse rates compared with myeloablative conditioning," Blood, vol. 109, no. 8, pp. 3588-3594, 2007.

[6] M. Mielcarek and R. Storb, "Non-myeloablative hematopoietic cell transplantation as immunotherapy for hematologic malignancies," Cancer Treatment Reviews, vol. 29, no. 4, pp. 283-290, 2003.

[7] J. Schetelig, A. Kiani, M. Schmitz, G. Ehninger, and M. Bornhäuser, "T cell-mediated graft-versus-leukemia reactions after allogeneic stem cell transplantation," Cancer Immunology, Immunotherapy, vol. 54, no. 11, pp. 1043-1058, 2005.

[8] H. Quach, D. Ritchie, A. K. Stewart et al., "Mechanism of action of immunomodulatory drugs (IMiDS) in multiple myeloma," Leukemia, vol. 24, no. 1, pp. 22-32, 2010.

[9] D. Pardoll, "Does the immune system see tumors as foreign or self?” Annual Review of Immunology, vol. 21, pp. 807-839, 2003.

[10] A. Corthay, D. K. Skovseth, K. U. Lundin et al., "Primary antitumor immune response mediated by CD4+ T cells," Immunity, vol. 22, no. 3, pp. 371-383, 2005.

[11] Z. Qin and T. Blankenstein, "CD4+ T cell-mediated tumor rejection involves inhibition of angiogenesis that is dependent on IFN $\gamma$ receptor expression by nonhematopoietic cells," Immunity, vol. 12, no. 6, pp. 677-686, 2000.

[12] E. Fernandez-Cruz, B. A. Woda, and J. D. Feldman, "Elimination of syngeneic sarcomas in rats by a subset of $\mathrm{T}$ lymphocytes," Journal of Experimental Medicine, vol. 152, no. 4, pp. 823-841, 1980.

[13] P. D. Greenberg, M. A. Cheever, and A. Fefer, "Eradication of disseminated murine leukemia by chemoimmunotherapy with cyclophosphamide and adoptively transferred immune syngeneic Lyt-1+2- lymphocytes," Journal of Experimental Medicine, vol. 154, no. 3, pp. 952-963, 1981.

[14] F. Ossendorp, E. Mengedé, M. Camps, R. Filius, and C. J. M. Melief, "Specific T helper cell requirement for optimal induction of cytotoxic $\mathrm{T}$ lymphocytes against major histocompatibility complex class II negative tumors," Journal of Experimental Medicine, vol. 187, no. 5, pp. 693-702, 1998.
[15] H. I. Levitsky, A. Lazenby, R. J. Hayashi, and D. M. Pardoll, "In vivo priming of two distinct antitumor effector populations: the role of MHC class I expression," Journal of Experimental Medicine, vol. 179, no. 4, pp. 1215-1224, 1994.

[16] B. Bogen, L. Munthe, A. Sollien et al., "Naive CD4+ T cells confer idiotype-specific tumor resistance in the absence of antibodies," European Journal of Immunology, vol. 25, no. 11, pp. 3079-3086, 1995.

[17] A. Corthay, K. B. Lorvik, and B. Bogen, "Is secretion of tumour-specific antigen important for cancer eradication by $\mathrm{CD}^{+}{ }^{+} \mathrm{T}$ cells? - implications for cancer immunotherapy by adoptive T cell transfer," Scandinavian Journal of Immunology, vol. 73, no. 6, pp. 527-530, 2011.

[18] Z. Dembic, K. Schenck, and B. Bogen, "Dendritic cells purified from myeloma are primed with tumor-specific antigen (idiotype) and activate CD4+ T cells," Proceedings of the National Academy of Sciences of the United States of America, vol. 97, no. 6, pp. 2697-2702, 2000.

[19] Z. Dembic, J. A. Røttingen, J. Dellacasagrande, K. Schenck, and B. Bogen, "Phagocytic dendritic cells from myelomas activate tumor-specific T cells at a single cell level," Blood, vol. 97, no. 9, pp. 2808-2814, 2001.

[20] H. Ogawara, H. Handa, T. Yamazaki et al., "High Th1/Th2 ratio in patients with multiple myeloma," Leukemia Research, vol. 29, no. 2, pp. 135-140, 2005.

[21] M. A. Frassanito, A. Cusmai, and F. Dammacco, "Deregulated cytokine network and defective Th1 immune response in multiple myeloma," Clinical and Experimental Immunology, vol. 125, no. 2, pp. 190-197, 2001.

[22] F. Mozaffari, L. Hansson, S. Kiaii et al., "Signalling molecules and cytokine production in T cells of multiple myelomaincreased abnormalities with advancing stage," British Journal of Haematology, vol. 124, no. 3, pp. 315-324, 2004.

[23] F. Tsushima, S. Yao, T. Shin et al., "Interaction between B7$\mathrm{H} 1$ and PD-1 determines initiation and reversal of T-cell anergy," Blood, vol. 110, no. 1, pp. 180-185, 2007.

[24] Y. Latchman, C. R. Wood, T. Chernova et al., "PD-L2 is a second ligand for PD-1 and inhibits T cell activation," Nature Immunology, vol. 2, no. 3, pp. 261-268, 2001.

[25] M. S. Cragg and M. J. Glennie, "Antibody specificity controls in vivo effector mechanisms of anti-CD20 reagents," Blood, vol. 103, no. 7, pp. 2738-2743, 2004.

[26] A. Di Bernardo, P. MacOr, C. Guarnotta et al., "Humoral immunotherapy of multiple myeloma: perspectives and perplexities," Expert Opinion on Biological Therapy, vol. 10, no. 6, pp. 863-873, 2010.

[27] K. A. Gelderman, S. Tomlinson, G. D. Ross, and A. Gorter, "Complement function in mAb-mediated cancer immunotherapy," Trends in Immunology, vol. 25, no. 3, pp. 158164, 2004.

[28] P. G. Richardson, S. Lonial, A. J. Jakubowiak, J. L. Harousseau, and K. C. Anderson, "Monoclonal antibodies in the treatment of multiple myeloma," British Journal of Haematology, 2011.

[29] M. J. Smyth, D. I. Godfrey, and J. A. Trapani, "A fresh look at tumor immunosurveillance and immunotherapy," Nature Immunology, vol. 2, no. 4, pp. 293-299, 2001.

[30] J. M. Kelly, P. K. Darcy, J. L. Markby et al., "Induction of tumor-specific T cell memory by NK cell-mediated tumor rejection," Nature Immunology, vol. 3, no. 1, pp. 83-90, 2002.

[31] S. Patil and T. Schwarer, "Natural killer cells-new understanding of basic biology may lead to more effective allogeneic haematopoietic stem cell transplantation: Review," Internal Medicine Journal, vol. 39, no. 10, pp. 639-647, 2009. 
[32] L. L. Lanier, "NK cell recognition," Annual Review of Immunology, vol. 23, pp. 225-274, 2005.

[33] L. F. Porrata, D. A. Gastineau, D. Padley, K. Bundy, and S. N. Markovic, "Re-infused autologous graft natural killer cells correlates with absolute lymphocyte count recovery after autologous stem cell transplantation," Leukemia and Lymphoma, vol. 44, no. 6, pp. 997-1000, 2003.

[34] M. Jarahian, C. Watzl, Y. Issa, P. Altevogt, and F. Momburg, "Blockade of natural killer cell-mediated lysis by NCAM140 expressed on tumor cells," International Journal of Cancer, vol. 120, no. 12, pp. 2625-2634, 2007.

[35] E. Carbone, P. Neri, M. Mesuraca et al., "HLA class I, NKG2D, and natural cytotoxicity receptors regulate multiple myeloma cell recognition by natural killer cells," Blood, vol. 105, no. 1, pp. 251-258, 2005.

[36] C. Frohn, M. Höppner, P. Schlenke, H. Kirchner, P. Koritke, and J. Luhm, "Anti-myeloma activity of natural killer lymphocytes," British Journal of Haematology, vol. 119, no. 3, pp. 660-664, 2002.

[37] G. Tricot, D. H. Vesole, S. Jagannath, J. Hilton, N. Munshi, and B. Barlogie, "Graft-versus-myeloma effect: proof of principle,” Blood, vol. 87, no. 3, pp. 1196-1198, 1996.

[38] E. Alici, T. Sutlu, B. Björkstrand et al., "Autologous antitumor activity by NK cells expanded from myeloma patients using GMP-compliant components," Blood, vol. 111, no. 6, pp. 3155-3162, 2008.

[39] J. Shi, G. Tricot, S. Szmania et al., "Infusion of haplo-identical killer immunoglobulin-like receptor ligand mismatched NK cells for relapsed myeloma in the setting of autologous stem cell transplantation," British Journal of Haematology, vol. 143, no. 5, pp. 641-653, 2008.

[40] R. D. Brown, B. Pope, A. Murray et al., "Dendritic cells from patients with myeloma are numerically normal but functionally defective as they fail to up-regulate CD80 (B7-1) expression after huCD40LT stimulation because of inhibition by transforming growth factor- $\beta 1$ and interleukin-10," Blood, vol. 98, no. 10, pp. 2992-2998, 2001.

[41] S. Wang, S. Hong, J. Yang et al., "Optimizing immunotherapy in multiple myeloma: restoring the function of patients' monocyte-derived dendritic cells by inhibiting p38 or activating MEK/ERK MAPK and neutralizing interleukin-6 in progenitor cells," Blood, vol. 108, no. 13, pp. 4071-4077, 2006.

[42] M. Ratta, F. Fagnoni, A. Curti et al., "Dendritic cells are functionally defective in multiple myeloma: the role of interleukin-6," Blood, vol. 100, no. 1, pp. 230-237, 2002.

[43] Y. Onishi, Z. Fehervari, T. Yamaguchi, and S. Sakaguchi, "Foxp3+ natural regulatory T cells preferentially form aggregates on dendritic cells in vitro and actively inhibit their maturation," Proceedings of the National Academy of Sciences of the United States of America, vol. 105, no. 29, pp. 1011310118, 2008.

[44] C. G. Drake, E. Jaffee, and D. M. Pardoll, "Mechanisms of Immune Evasion by Tumors," Advances in Immunology, vol. 90, pp. 51-81, 2006.

[45] W. Zou, "Regulatory T cells, tumour immunity and immunotherapy," Nature Reviews Immunology, vol. 6, no. 4, pp. 295-307, 2006.

[46] L. Peng, J. Kjaergäard, G. E. Plautz et al., "Tumor-induced L-selectinhigh suppressor $\mathrm{T}$ cells mediate potent effector T cell blockade and cause failure of otherwise curative adoptive immunotherapy," Journal of Immunology, vol. 169, no. 9, pp. 4811-4821, 2002.

[47] G. Zhou and H. I. Levitsky, "Natural regulatory T cells and de novo-induced regulatory $\mathrm{T}$ cells contribute independently to tumor-specific tolerance," Journal of Immunology, vol. 178, no. 4, pp. 2155-2162, 2007.

[48] T. J. Curiel, G. Coukos, L. Zou et al., "Specific recruitment of regulatory $\mathrm{T}$ cells in ovarian carcinoma fosters immune privilege and predicts reduced survival," Nature Medicine, vol. 10, no. 9, pp. 942-949, 2004.

[49] E. Y. Woo, C. S. Chu, T. J. Goletz et al., "Regulatory CD4+CD25+ T cells in tumors from patients with early-stage non-small cell lung cancer and late-stage ovarian cancer," Cancer Research, vol. 61, no. 12, pp. 4766-4772, 2001.

[50] U. K. Liyanage, T. T. Moore, H. G. Joo et al., "Prevalence of regulatory $\mathrm{T}$ cells is increased in peripheral blood and tumor microenvironment of patients with pancreas or breast adenocarcinoma," Journal of Immunology, vol. 169, no. 5, pp. 2756-2761, 2002.

[51] M. Beyer and J. L. Schultze, "Regulatory T cells in cancer," Blood, vol. 108, no. 3, pp. 804-811, 2006.

[52] M. Beyer, M. Kochanek, T. Giese et al., "In vivo peripheral expansion of naive $\mathrm{CD} 4+\mathrm{CD} 25$ high FoxP3+ regulatory $\mathrm{T}$ cells in patients with multiple myeloma," Blood, vol. 107, no. 10, pp. 3940-3949, 2006.

[53] S. Feyler, M. Von Lilienfeld-Toal, S. Jarmin et al., "CD4+CD25+FoxP3+ regulatory T cells are increased whilst CD3+CD4-CD8 $-\alpha \beta$ TCR + Double Negative T cells are decreased in the peripheral blood of patients with multiple myeloma which correlates with disease burden," British Journal of Haematology, vol. 144, no. 5, pp. 686-695, 2009.

[54] A. M. Ercolini, B. H. Ladle, E. A. Manning et al., "Recruitment of latent pools of high-avidity CD8+ $\mathrm{T}$ cells to the antitumor immune response," Journal of Experimental Medicine, vol. 201, no. 10, pp. 1591-1602, 2005.

[55] F. Ghiringhelli, N. Larmonier, E. Schmitt et al., "CD4+CD25+ regulatory T cells suppress tumor immunity but are sensitive to cyclophosphamide which allows immunotherapy of established tumors to be curative," European Journal of Immunology, vol. 34, no. 2, pp. 336-344, 2004.

[56] J. Shimizu, S. Yamazaki, and S. Sakaguchi, "Induction of tumor immunity by removing CD25+CD4+ T cells: a common basis between tumor immunity and autoimmunity," Journal of Immunology, vol. 163, no. 10, pp. 5211-5218, 1999.

[57] H. Tanaka, J. Tanaka, J. Ø. Kjaergaard, and S. Shu, "Depletion of CD4+CD25+ regulatory cells augments the generation of specific immune T cells in tumor-draining lymph nodes," Journal of Immunotherapy, vol. 25, no. 3, pp. 207-217, 2002.

[58] E. Jones, M. Dahm-Vicker, A. K. Simon et al., "Depletion of CD25+ regulatory cells results in suppression of melanoma growth and induction of autoreactivity in mice," Cancer Immun, vol. 2, p. 1, 2002.

[59] W. Zou, "Immunosuppressive networks in the tumour environment and their therapeutic relevance," Nature Reviews Cancer, vol. 5, no. 4, pp. 263-274, 2005.

[60] M. Abe, K. Hiura, J. Wilde et al., "Osteoclasts enhance myeloma cell growth and survival via cell-cell contact: a vicious cycle between bone destruction and myeloma expansion," Blood, vol. 104, no. 8, pp. 2484-2491, 2004.

[61] S. Yaccoby, M. J. Wezeman, A. Henderson et al., "Cancer and the Microenvironment: Myeloma-Osteoclast Interactions as a Model," Cancer Research, vol. 64, no. 6, pp. 2016-2023, 2004.

[62] S. Yaccoby, M. J. Wezeman, M. Zangari et al., "Inhibitory effects of osteoblasts and increased bone formation on myeloma in novel culture systems and a myelomatous mouse model," Haematologica, vol. 91, no. 2, pp. 192-199, 2006. 
[63] X. Li, A. Pennisi, and S. Yaccoby, "Role of decorin in the antimyeloma effects of osteoblasts," Blood, vol. 112, no. 1, pp. 159-168, 2008.

[64] S. Barillé-Nion and R. Bataille, "New insights in myeloma-induced osteolysis," Leukemia and Lymphoma, vol. 44, no. 9, pp. 1463-1467, 2003.

[65] I. Grigorieva, X. Thomas, and J. Epstein, "The bone marrow stromal environment is a major factor in myeloma cell resistance to dexamethasone," Experimental Hematology, vol. 26, no. 7, pp. 597-603, 1998.

[66] J. S. Damiano, A. E. Cress, L. A. Hazlehurst, A. A. Shtil, and W. S. Dalton, "Cell adhesion mediated drug resistance (CAM-DR): role of integrins and resistance to apoptosis in human myeloma cell lines," Blood, vol. 93, no. 5, pp. 16581667, 1999.

[67] D. L. Lacey, E. Timms, H. L. Tan et al., "Osteoprotegerin ligand is a cytokine that regulates osteoclast differentiation and activation," Cell, vol. 93, no. 2, pp. 165-176, 1998.

[68] J. Corre, K. Mahtouk, M. Attal et al., "Bone marrow mesenchymal stem cells are abnormal in multiple myeloma," Leukemia, vol. 21, no. 5, pp. 1079-1088, 2007.

[69] S. R. Wallace, M. M. Oken, K. L. Lunetta, A. PanoskaltsisMortari, and A. M. Masellis, "Abnormalities of bone marrow mesenchymal cells in multiple myeloma patients," Cancer, vol. 91, no. 7, pp. 1219-1230, 2001.

[70] L. Garderet, C. Mazurier, A. Chapel et al., "Mesenchymal stem cell abnormalities in patients with multiple myeloma," Leukemia and Lymphoma, vol. 48, no. 10, pp. 2032-2041, 2007.

[71] D. K. Banerjee, M. V. Dhodapkar, E. Matayeva, R. M. Steinman, and K. M. Dhodapkar, "Expansion of FOXP3high regulatory $\mathrm{T}$ cells by human dendritic cells (DCs) in vitro and after injection of cytokine-matured DCs in myeloma patients," Blood, vol. 108, no. 8, pp. 2655-2661, 2006.

[72] L. Houet and H. Veelken, "Active immunotherapy of multiple myeloma," European Journal of Cancer, vol. 42, no. 11, pp. 1653-1660, 2006.

[73] N. Sakato and H. N. Eisen, "Antibodies to idiotypes of isologous immunoglobulins," Journal of Experimental Medicine, vol. 141, no. 6, pp. 1411-1426, 1975.

[74] S. Bergenbrant, Q. Yi, A. Osterborg et al., "T-cell stimulation induced by idiotypes on monoclonal immunoglobulins in patients with monoclonal gammopathies," Scandinavian Journal of Immunology, vol. 38, no. 6, pp. 529-534, 1993.

[75] Q. Yi, A. Osterborg, S. Bergenbrant, H. Mellstedt, G. Holm, and A. K. Lefvert, "Idiotype-reactive T-cell subsets and tumor load in monoclonal gammopathies," Blood, vol. 86, no. 8, pp. 3043-3049, 1995.

[76] G. F. Lauritzsen, S. Weiss, Z. Dembic, and B. Bogen, "Naive idiotype-specific $\mathrm{CD} 4+\mathrm{T}$ cells and immunosurveillance of Bcell tumors," Proceedings of the National Academy of Sciences of the United States of America, vol. 91, no. 12, pp. 5700-5704, 1994.

[77] Y. Li, M. Bendandi, Y. Deng et al., "Tumor-specific recognition of human myeloma cells by idiotype-induced CD8+ T cells," Blood, vol. 96, no. 8, pp. 2828-2833, 2000.

[78] Y. J. Wen, B. Barlogie, and Q. Yi, "Idiotype-specific cytotoxic $\mathrm{T}$ lymphocytes in multiple myeloma: evidence for their capacity to lyse autologous primary tumor cells," Blood, vol. 97, no. 6, pp. 1750-1755, 2001.

[79] Y. J. Wen, M. Ling, R. Bailey-Wood, and S. H. Lim, "Idiotypic protein-pulsed adherent peripheral blood mononuclear cellderived dendritic cells prime immune system in multiple myeloma," Clinical Cancer Research, vol. 4, no. 4, pp. 957962, 1998.

[80] L. Hansson, H. Rabbani, J. Fagerberg, A. Österborg, and H. Mellstedt, "T-cell epitopes within the complementaritydetermining and framework regions of the tumor-derived immunoglobulin heavy chain in multiple myeloma," Blood, vol. 101, no. 12, pp. 4930-4936, 2003.

[81] Q. Yi, "Novel immunotherapies," Cancer Journal, vol. 15, no. 6, pp. 502-510, 2009.

[82] Q. Yi, I. Eriksson, W. He, G. Holm, H. Mellstedt, and A. Österborg, "Idiotype-specific T lymphocytes in monoclonal gammopathies: evidence for the presence of $\mathrm{CD} 4+$ and CD8+ subsets," British Journal of Haematology, vol. 96, no. 2, pp. 338-345, 1997.

[83] S. Dabadghao, S. Bergenbrant, D. Anton, W. He, G. Holm, and Q. Yi, "Anti-idiotypic T-cell activation in multiple myeloma induced by M- component fragments presented by dendritic cells," British Journal of Haematology, vol. 100, no. 4, pp. 647-654, 1998.

[84] S. Romagnani and T. Mosmann, "Human $\mathrm{T}(\mathrm{H}) 1$ and $\mathrm{T}(\mathrm{H}) 2$ subsets: doubt no more," Immunology Today, vol. 12, no. 8, pp. 256-257, 1991.

[85] P. Salgame, J. S. Abrams, C. Clayberger et al., "Differing lymphokine profiles of functional subsets of human CD4 and CD8 T cell clones," Science, vol. 254, no. 5029, pp. 279-282, 1991.

[86] S. Bergenbrant, Q. Yi, A. Österborg et al., "Modulation of anti-idiotypic immune response by immunization with the autologous M-component protein in multiple myeloma patients," British Journal of Haematology, vol. 92, no. 4, pp. 840-846, 1996.

[87] A. Österborg, Q. Yi, L. Henriksson et al., "Idiotype immunization combined with granulocyte-macrophage colonystimulating factor in myeloma patients induced type I, major histocompatibility complex-restricted, CD8- and CD4-specific T-cell responses," Blood, vol. 91, no. 7, pp. 2459-2466, 1998.

[88] M. Massaia, P. Borrione, S. Battaglio et al., "Idiotype vaccination in human myeloma: generation of tumor-specific immune responses after high-dose chemotherapy," Blood, vol. 94, no. 2, pp. 673-683, 1999.

[89] M. Coscia, S. Mariani, S. Battaglio et al., "Long-term followup of idiotype vaccination in human myeloma as a maintenance therapy after high-dose chemotherapy," Leukemia, vol. 18, no. 1, pp. 139-145, 2004.

[90] T. Rasmussen, L. Hansson, A. Österborg, H. E. Johnsen, and H. Mellstedt, "Idiotype vaccination in multiple myeloma induced a reduction of circulating clonal tumor B cells," Blood, vol. 101, no. 11, pp. 4607-4610, 2003.

[91] C. Bertinetti, K. Zirlik, K. Heining-Mikesch et al., "Phase I trial of a novel intradermal idiotype vaccine in patients with advanced B-cell lymphoma: specific immune responses despite profound immunosuppression," Cancer Research, vol. 66, no. 8, pp. 4496-4502, 2006.

[92] V. L. Reichardt, C. Y. Okada, A. Liso et al., "Idiotype vaccination using dendritic cells after autologous peripheral blood stem cell transplantation for multiple myeloma-a feasibility study," Blood, vol. 93, no. 7, pp. 2411-2419, 1999.

[93] V. L. Reichardt, C. Milazzo, W. Brugger, H. Einsele, L. Kanz, and P. Brossart, "Idiotype vaccination of multiple myeloma patients using monocyte-derived dendritic cells," Haematologica, vol. 88, no. 10, pp. 1139-1149, 2003. 
[94] S. Titzer, O. Christensen, O. Manzke et al., "Vaccination of multiple myeloma patients with idiotype-pulsed dendritic cells: immunological and clinical aspects," British Journal of Haematology, vol. 108, no. 4, pp. 805-816, 2000.

[95] S. H. Lim and R. Bailey-Wood, "Idiotypic protein-pulsed dendritic cell vaccination in multiple myeloma," International Journal of Cancer, vol. 83, no. 2, pp. 215-222, 1999.

[96] A. Liso, K. E. Stockerl-Goldstein, S. Auffermann-Gretzinger et al., "Idiotype Vaccination Using Dendritic Cells after Autologous Peripheral Blood Progenitor Cell Transplantation for Multiple Myeloma," Biology of Blood and Marrow Transplantation, vol. 6, no. 6, pp. 621-627, 2000.

[97] P. Brossart, A. Schneider, P. Dill et al., "The epithelial tumor antigen MUC1 is expressed in hematological malignancies and is recognized by MUC1-specific cytotoxic Tlymphocytes," Cancer Research, vol. 61, no. 18, pp. 68466850, 2001.

[98] S. H. Lim, Z. Wang, M. Chiriva-Internati, and Y. Xue, "Sperm protein 17 is a novel cancer-testis antigen in multiple myeloma," Blood, vol. 97, no. 5, pp. 1508-1510, 2001.

[99] S. Szmania, G. Tricot, and F. van Rhee, "NY-ESO-1 immunotherapy for multiple myeloma," Leukemia and Lymphoma, vol. 47, no. 10, pp. 2037-2048, 2006.

[100] D. Atanackovic, J. Arfsten, Y. Cao et al., "Cancer-testis antigens are commonly expressed in multiple myeloma and induce systemic immunity following allogeneic stem cell transplantation," Blood, vol. 109, no. 3, pp. 1103-1112, 2007.

[101] R. B. Batchu, A. M. Moreno, S. M. Szmania et al., "Protein transduction of dendritic cells for NY-ESO-1-based immunotherapy of myeloma," Cancer Research, vol. 65, no. 21, pp. 10041-10049, 2005.

[102] M. Hundemer, S. Schmidt, M. Condomines et al., "Identification of a new HLA-A2-restricted T-cell epitope within HM1.24 as immunotherapy target for multiple myeloma," Experimental Hematology, vol. 34, no. 4, pp. 486-496, 2006.

[103] J. Burchell, J. Taylor-Papadimitriou, M. Boshell, S. Gendler, and T. Duhig, "A short sequence, within the amino acid tandem repeat of a cancer-associated mucin, contains immunodominant epitopes," International Journal of Cancer, vol. 44, no. 4, pp. 691-696, 1989.

[104] T. Takahashi, Y. Makiguchi, Y. Hinoda et al., "Expression of MUC1 on myeloma cells and induction of HLA-unrestricted CTL against MUC1 from a multiple myeloma patient," Journal of Immunology, vol. 153, no. 5, pp. 2102-2109, 1994.

[105] C. Rosenfeld, M. A. Cheever, and A. Gaiger, "WT1 in acute leukemia, chronic myelogenous leukemia and myelodysplastic syndrome: therapeutic potential of WT1 targeted therapies," Leukemia, vol. 17, no. 7, pp. 1301-1312, 2003.

[106] C. Scheibenbogen, A. Letsch, E. Thiel et al., "CD8 T-cell responses to Wilms tumor gene product WT1 and proteinase 3 in patients with acute myeloid leukemia," Blood, vol. 100, no. 6, pp. 2132-2137, 2002.

[107] T. Azuma, T. Otsuki, K. Kuzushima, C. J. Froelich, S. Fujita, and M. Yasukawa, "Myeloma cells are highly sensitive to the granule exocytosis pathway mediated by WT1-specific cytotoxic T lymphocytes," Clinical Cancer Research, vol. 10, no. 21, pp. 7402-7412, 2004.

[108] A. Matsuda, Y. Suzuki, G. Honda et al., "Large-scale identification and characterization of human genes that activate NF$\kappa \mathrm{B}$ and MAPK signaling pathways," Oncogene, vol. 22, no. 21, pp. 3307-3318, 2003.

[109] T. Goto, S. J. Kennel, M. Abe et al., "A novel membrane antigen selectively expressed on terminally differentiated human B cells," Blood, vol. 84, no. 6, pp. 1922-1930, 1994.
[110] A. Jalili, S. Ozaki, T. Hara et al., "Induction of HM1.24 peptide-specific cytotoxic $\mathrm{T}$ lymphocytes by using peripheral-blood stem-cell harvests in patients with multiple myeloma," Blood, vol. 106, no. 10, pp. 3538-3545, 2005.

[111] M. Chiriva-Internati, R. Ferraro, M. Prabhakar et al., "The pituitary tumor transforming gene 1 (PTTG-1): an immunological target for multiple myeloma," Journal of Translational Medicine, vol. 6, article no. 15, 2008.

[112] C. A. Maxwell, E. Rasmussen, F. Zhan et al., "RHAMM expression and isoform balance predict aggressive disease and poor survival in multiple myeloma," Blood, vol. 104, no. 4, pp. 1151-1158, 2004.

[113] M. Crainie, A. R. Belch, M. J. Mant, and L. M. Pilarski, "Overexpression of the receptor for hyaluronan-mediated motility (RHAMM) characterizes the malignant clone in multiple myeloma: identification of three distinct RHAMM variants," Blood, vol. 93, no. 5, pp. 1684-1696, 1999.

[114] J. Greiner, M. Schmitt, L. Li et al., "Expression of tumor-associated antigens in acute myeloid leukemia: implications for specific immunotherapeutic approaches," Blood, vol. 108, no. 13, pp. 4109-4117, 2006.

[115] J. Greiner, L. Li, M. Ringhoffer et al., "Identification and characterization of epitopes of the receptor for hyaluronic acid-mediated motility (RHAMM/CD168) recognized by CD8+ T cells of HLA-A2-positive patients with acute myeloid leukemia," Blood, vol. 106, no. 3, pp. 938-945, 2005.

[116] M. Schmitt, A. Schmitt, M. T. Rojewski et al., "RHAMM-R3 peptide vaccination in patients with acute myeloid leukemia, myelodysplastic syndrome, and multiple myeloma elicits immunologic and clinical responses," Blood, vol. 111, no. 3, pp. 1357-1365, 2008.

[117] J. Greiner, M. Ringhoffer, M. Taniguchi et al., "Receptor for hyaluronan acid-mediated motility (RHAMM) is a new immunogenic leukemia-associated antigen in acute and chronic myeloid leukemia," Experimental Hematology, vol. 30, no. 9, pp. 1029-1035, 2002.

[118] J. Greiner, H. Döhner, and M. Schmitt, "Cancer vaccines for patients with acute myeloid leukemia-definition of leukemia-associated antigens and current clinical protocols targeting these antigens," Haematologica, vol. 91, no. 12, pp. 1653-1661, 2006.

[119] J. Chen, A. Schmitt, D. Bunjes, B. Chen, and M. Schmitt, "The receptor for hyaluronic acid-mediated motility induces specific CD8+ T cell response in healthy donors and patients with chronic myeloid leukemia after allogeneic stem cell transplantation," International Journal of Oncology, vol. 30, no. 5, pp. 1119-1127, 2007.

[120] M. V. Dhodapkar, K. Osman, J. Teruya-Feldstein et al., "Expression of cancer/testis (CT) antigens MAGE-A1, MAGEA3, MAGE-A4, CT-7, and NY-ESO-1 in malignant gammopathies is heterogeneous and correlates with site, stage and risk status of disease," Cancer Immunity, vol. 3, 9 pages, 2003.

[121] A. A. Jungbluth, S. Ely, M. DiLiberto et al., "The cancer-testis antigens CT7 (MAGE-C1) and MAGE-A3/6 are commonly expressed in multiple myeloma and correlate with plasmacell proliferation," Blood, vol. 106, no. 1, pp. 167-174, 2005.

[122] C. Pellat-Deceunynck, M. P. Mellerin, N. Labarrière et al., "The cancer germ-line genes MAGE-1, MAGE-3 and PRAME are commonly expressed by human myeloma cells," European Journal of Immunology, vol. 30, no. 3, pp. 803-809, 2000. 
[123] N. Van Baren, F. Brasseur, D. Godelaine et al., "Genes encoding tumor-specific antigens are expressed in human myeloma cells," Blood, vol. 94, no. 4, pp. 1156-1164, 1999.

[124] F. Van Rhee, S. M. Szmania, F. Zhan et al., "NY-ESO-1 is highly expressed in poor-prognosis multiple myeloma and induces spontaneous humoral and cellular immune responses," Blood, vol. 105, no. 10, pp. 3939-3944, 2005.

[125] Z. Wang, Y. Zhang, H. Liu, E. Salati, M. Chiriva-Internati, and S. H. Lim, "Gene expression and immunologic consequence of SPAN-Xb in myeloma and other hematologic malignancies," Blood, vol. 101, no. 3, pp. 955-960, 2003.

[126] O. Goodyear, K. Piper, N. Khan et al., "CD8+T cells specific for cancer germline gene antigens are found in many patients with multiple myeloma, and their frequency correlates with disease burden," Blood, vol. 106, no. 13, pp. 4217-4224, 2005.

[127] M. Condomines, D. Hose, P. Raynaud et al., "Cancer/testis genes in multiple myeloma: expression patterns and prognosis value determined by microarray analysis," Journal of Immunology, vol. 178, no. 5, pp. 3307-3315, 2007.

[128] A. D. Atanackovic, T. Luetkens, Y. Hildebrandt et al., "Longitudinal analysis and prognostic effect of cancer-testis antigen expression in multiple myeloma," Clinical Cancer Research, vol. 15, no. 4, pp. 1343-1352, 2009.

[129] M. Chiriva-Internati, L. Mirandola, Y. Yu et al., "Cancer testis antigen, ropporin, is a potential target for multiple myeloma immunotherapy," Journal of Immunotherapy, vol. 34, no. 6, pp. 490-499, 2011.

[130] M. van Duin, A. Broyl, Y. de Knegt et al., "Cancer testis antigens in newly diagnosed and relapse multiple myeloma: prognostic markers and potential targets for immunotherapy," Haematologica, vol. 96, no. 11, pp. 1662-1669, 2011.

[131] G. Mulligan, C. Mitsiades, B. Bryant et al., "Gene expression profiling and correlation with outcome in clinical trials of the proteasome inhibitor bortezomib," Blood, vol. 109, no. 8, pp. 3177-3188, 2007.

[132] S. S. Sahota, C. M. Goonewardena, C. D. O. Cooper et al., "PASD1 is a potential multiple myeloma-associated antigen," Blood, vol. 108, no. 12, pp. 3953-3955, 2006.

[133] C. Pabst, J. Zustin, F. Jacobsen et al., "Expression and prognostic relevance of MAGE-C1/CT7 and MAGE-C2/CT10 in osteolytic lesions of patients with multiple myeloma," Experimental and Molecular Pathology, vol. 89, no. 2, pp. 175$181,2010$.

[134] V. C. C. Andrade, A. L. Vettore, R. S. Felix et al., "Prognostic impact of cancer/testis antigen expression in advanced stage multiple myeloma patients," Cancer Immunity, vol. 8, 2 pages, 2008.

[135] F. de Carvalho, A. L. Vettore, R. J. Inaoka et al., "Evaluation of LAGE-1 and NY-ESO-1 expression in multiple myeloma patients to explore possible benefits of their homology for immunotherapy," Cancer Immunity, vol. 11, pp. 1-5, 2011.

[136] J. Rosenblatt and D. Avigan, "Cellular immunotherapy for multiple myeloma," Best Practice \& Research Clinical Haematology, vol. 21, no. 3, pp. 559-577, 2008.

[137] T. Hayashi, T. Hideshima, M. Akiyama et al., "Ex vivo induction of multiple myeloma-specific cytotoxic T lymphocytes," Blood, vol. 102, no. 4, pp. 1435-1442, 2003.

[138] K. M. Dhodapkar, J. Krasovsky, B. Williamson, and M. V. Dhodapkar, "Antitumor monoclonal antibodies enhance cross-presentation of cellular antigens and the generation of myeloma-specific killer T cells by dendritic cells," Journal of Experimental Medicine, vol. 195, no. 1, pp. 125-133, 2002.

[139] Y. J. Wen, R. Min, G. Tricot, B. Barlogie, and Q. Yi, “Tumor lysate-specific cytotoxic T lymphocytes in multiple myeloma: promising effector cells for immunotherapy," Blood, vol. 99, no. 9, pp. 3280-3285, 2002.

[140] K. Rezvani, A. S. M. Yong, S. Mielke et al., "Leukemia-associated antigen-specific T-cell responses following combined PR1 and WT1 peptide vaccination in patients with myeloid malignancies," Blood, vol. 111, no. 1, pp. 236-242, 2008.

[141] J. Greiner, A. Schmitt, K. Giannopoulos et al., "High-dose RHAMM-R3 peptide vaccination for patients with acute myeloid leukemia, myelodysplastic syndrome and multiple myeloma," Haematologica, vol. 95, no. 7, pp. 1191-1197, 2010.

[142] S. K. Kim, T. N. Nguyen Pham, T. M. Nguyen Hoang et al., "Induction of myeloma-specific cytotoxic T lymphocytes ex vivo by CD40-activated B cells loaded with myeloma tumor antigens," Annals of Hematology, vol. 88, no. 11, pp. 1113$1123,2009$.

[143] R. H. Vonderheide, J. L. Schultze, K. S. Anderson et al., "Equivalent induction of telomerase-specific cytotoxic T lymphocytes from tumor-bearing patients and healthy individuals," Cancer Research, vol. 61, no. 23, pp. 8366-8370, 2001.

[144] B. Minev, J. Hipp, H. Firat, J. D. Schmidt, P. LangladeDemoyen, and M. Zanetti, "Cytotoxic T cell immunity against telomerase reverse transcriptase in humans," Proceedings of the National Academy of Sciences of the United States of America, vol. 97, no. 9, pp. 4796-4801, 2000.

[145] F. Kryukov, D. Ocadlíková, L. Kovárová, I. Buresová, R. Hájek, and J. Michálek, "In vitro activation of cytotoxic Tlymphocytes by hTERT-pulsed dendritic cells," Journal of Immunotoxicology, vol. 6, no. 4, pp. 243-248, 2009.

[146] J. Michalek, D. Ocadlikova, E. Matejkova et al., "Individual myeloma-specific T-cell clones eliminate tumour cells and correlate with clinical outcomes in patients with multiple myeloma: research paper," British Journal of Haematology, vol. 148, no. 6, pp. 859-867, 2010.

[147] H. Noto, T. Takahashi, Y. Makiguchi, T. Hayashi, Y. Hinoda, and K. Imai, "Cytotoxic T lymphocytes derived from bone marrow mononuclear cells of multiple myeloma patients recognize an underglycosylated form of MUC1 mucin," International Immunology, vol. 9, no. 5, pp. 791-798, 1997.

[148] D. Ocadlikova, F. Kryukov, K. Mollova et al., "Generation of myeloma-specific T cells using dendritic cells loaded with MUC1- and hTERT- drived nonapeptides or myeloma cell apoptotic bodies," Neoplasma, vol. 57, no. 5, pp. 455-464, 2010.

[149] S. Wilde, D. Sommermeyer, B. Frankenberger et al., "Dendritic cells pulsed with RNA encoding allogeneic MHC and antigen induce $\mathrm{T}$ cells with superior antitumor activity and higher TCR functional avidity," Blood, vol. 114, no. 10, pp. 2131-2139, 2009.

[150] S. Onizuka, I. Tawara, J. Shimizu, S. Sakaguchi, T. Fujita, and E. Nakayama, "Tumor rejection by in vivo administration of anti-CD25 (interleukin-2 receptor $\alpha$ ) monoclonal antibody," Cancer Research, vol. 59, no. 13, pp. 3128-3133, 1999.

[151] A. M. Krieg, "CpG motifs in bacterial DNA and their immune effects," Annual Review of Immunology, vol. 20, pp. 709-760, 2002.

[152] A. W. Butch, K. A. Kelly, and N. C. Munshi, "Dendritic cells derived from multiple myeloma patients efficiently internalize different classes of myeloma protein," Experimental Hematology, vol. 29, no. 1, pp. 85-92, 2001.

[153] G. Cull, L. Durrant, C. Stainer, A. Haynes, and N. Russell, "Generation of anti-idiotype immune responses following vaccination with idiotype-protein pulsed dendritic cells in 
myeloma," British Journal of Haematology, vol. 107, no. 3, pp. 648-655, 1999.

[154] Q. Yi, R. Desikan, B. Barlogie, and N. Munshi, "Optimizing dendritic cell-based immunotherapy in multiple myeloma," British Journal of Haematology, vol. 117, no. 2, pp. 297-305, 2002.

[155] A. Curti, P. Tosi, P. Comoli et al., "Phase I/II clinical trial of sequential subcutaneous and intravenous delivery of dendritic cell vaccination for refractory multiple myeloma using patient-specific tumour idiotype protein or idiotype (VDJ)-derived class I-restricted peptides," British Journal of Haematology, vol. 139, no. 3, pp. 415-424, 2007.

[156] M. Bendandi, M. Rodríguez-Calvillo, S. Inogés et al., "Combined vaccination with idiotype-pulsed allogeneic dendritic cells and soluble protein idiotype for multiple myeloma patients relapsing after reduced-intensity conditioning allogeneic stem cell transplantation," Leukemia and Lymphoma, vol. 47, no. 1, pp. 29-37, 2006.

[157] J. Gong, D. Chen, M. Kashiwaba, and D. Kufe, "Induction of antitumor activity by immunization with fusions of dendritic and carcinoma cells," Nature Medicine, vol. 3, no. 5, pp. 558561, 1997.

[158] J. Gong, S. Koido, D. Chen et al., "Immunization against murine multiple myeloma with fusions of dendritic and plasmacytoma cells is potentiated by interleukin 12," Blood, vol. 99, no. 7, pp. 2512-2517, 2002.

[159] N. Raje, T. Hideshima, F. E. Davies et al., "Tumour cell/ dendritic cell fusions as a vaccination strategy for multiple myeloma," British Journal of Haematology, vol. 125, no. 3, pp. 343-352, 2004.

[160] S. Hao, X. Bi, S. Xu et al., "Enhanced antitumor immunity derived from a novel vaccine of fusion hybrid between dendritic and engineered myeloma cells," Experimental Oncology, vol. 26, no. 4, pp. 300-306, 2004.

[161] R. Walewska, I. Teobald, D. Dunnion et al., "Preclinical development of hybrid cell vaccines for multiple myeloma," European Journal of Haematology, vol. 78, no. 1, pp. 11-20, 2007.

[162] Y. Nefedova, S. Nagaraj, A. Rosenbauer, C. Muro-Cacho, S. M. Sebti, and D. I. Gabrilovich, "Regulation of dendritic cell differentiation and antitumor immune response in cancer by pharmacologic-selective inhibition of the Janus-activated kinase 2/signal transducers and activators of transcription 3 pathway," Cancer Research, vol. 65, no. 20, pp. 9525-9535, 2005.

[163] D. H. Yang, J. S. Park, C. J. Jin et al., "The dysfunction and abnormal signaling pathway of dendritic cells loaded by tumor antigen can be overcome by neutralizing VEGF in multiple myeloma," Leukemia Research, vol. 33, no. 5, pp. 665-670, 2009.

[164] R. B. Mailliard, A. Wankowicz-Kalinska, Q. Cai et al., “ $\alpha$ type-1 polarized dendritic cells: a novel immunization tool with optimized CTL-inducing activity," Cancer Research, vol. 64, no. 17, pp. 5934-5937, 2004.

[165] J. J. Lee, B. H. Choi, H. K. Kang et al., "Induction of multiple myeloma-specific cytotoxic T lymphocyte stimulation by dendritic cell pulsing with purified and optimized myeloma cell lysates," Leukemia and Lymphoma, vol. 48, no. 10, pp. 2022-2031, 2007.

[166] D. H. Yang, M. H. Kim, C. Y. Hong et al., "Alpha-type 1polarized dendritic cells loaded with apoptotic allogeneic myeloma cell line induce strong CTL responses against autologous myeloma cells," Annals of Hematology, vol. 89, no. 8, pp. 795-801, 2010.

[167] I. Borrello, E. M. Sotomayor, F. M. Rattis, S. K. Cooke, L. $\mathrm{Gu}$, and H. I. Levitsky, "Sustaining the graft-versus-tumor effect through posttransplant immunization with granulocyte-macrophage colony-stimulating factor (GM-CSF)producing tumor vaccines," Blood, vol. 95, no. 10, pp. 30113019, 2000.

[168] K. M. Williams, F. T. Hakim, R. E. Gress et al., "T cell immune reconstitution following lymphodepletion," Seminars in Immunology, vol. 19, no. 5, pp. 318-330, 2007.

[169] K. Luptakova, B. Glotzbecker, and H. Mills, "Lenalidomide decreases PD-1 expression, depletes regulatory T-cells and improves cellular response to a multiple myeloma/dendritic cell fusion vaccine in vitro," ASH Annual Meeting and Exposition, 2011.

[170] N. C. Fernandez, A. Lozier, C. Flament et al., "Dendritic cells directly trigger NK cell functions: cross-talk relevant in innate anti-tumor immune responses in vivo," Nature Medicine, vol. 5, no. 4, pp. 405-411, 1999.

[171] G. Ferlazzo, M. L. Tsang, L. Moretta, G. Melioli, R. M. Steinman, and C. Münz, "Human dendritic cells activate resting natural killer (NK) cells and are recognized via the NKp30 receptor by activated NK cells," Journal of Experimental Medicine, vol. 195, no. 3, pp. 343-351, 2002.

[172] M. A. Cooper, T. A. Fehniger, A. Fuchs, M. Colonna, and M. A. Caligiuri, "NK cell and DC interactions," Trends in Immunology, vol. 25, no. 1, pp. 47-52, 2004.

[173] H. Jonuleit, U. Kühn, G. Müller et al., "Pro-inflammatory cytokines and prostaglandins induce maturation of potent immunostimulatory dendritic cells under fetal calf serumfree conditions," European Journal of Immunology, vol. 27, no. 12, pp. 3135-3142, 1997.

[174] T. N. Nguyen-Pham, C. M. Im, T. A. Thi Nguyen et al., "Induction of myeloma-specific cytotoxic $\mathrm{T}$ lymphocytes responses by natural killer cells stimulated-dendritic cells in patients with multiple myeloma," Leukemia Research, vol. 35, no. 9, pp. 1241-1247, 2011.

[175] E Katodritou, E. Terpos, and J. North, "Tumor-primed natural killer cells from patients with multiple myeloma lyse autologous, NK-resistant, bone marrow-derived malignant plasma cells," American Journal of Hematology, vol. 86, no. 12, pp. 967-973, 2011.

[176] X. Wu, Y. Shao, Y. Tao et al., "Proteasome inhibitor lactacystin augments natural killer cell cytotoxicity of myeloma via downregulation of HLA class I," Biochemical and Biophysical Research Communications, vol. 415, no. 1, pp. 187-192, 2011.

[177] M. J. Smyth and D. I. Godfrey, "NKT cells and tumor immunity-a double-edged sword," Nature Immunology, vol. 1, no. 6, pp. 459-460, 2000.

[178] T. Azuma, T. Takahashi, A. Kunisato, T. Kitamura, and H. Hirai, "Human CD4+ CD25+ regulatory T cells suppress NKT cell functions," Cancer Research, vol. 63, no. 15, pp. 4516-4520, 2003.

[179] A. Sharabi and N. H. Ghera, "Breaking tolerance in a mouse model of multiple myeloma by chemoimmunotherapy," $A d v-$ ances in cancer research, vol. 107, pp. 1-37, 2010.

[180] G. Eberl, P. Brawand, and H. R. MacDonald, "Selective bystander proliferation of memory CD4+ and CD8+ T cells upon NK T or T cell activation," Journal of Immunology, vol. 165, no. 8, pp. 4305-4311, 2000.

[181] T. Nishimura, H. Kitamura, K. Iwakabe et al., "The interface between innate and acquired immunity: glycolipid antigen 
presentation by CD1d-expressing dendritic cells to NKT cells induces the differentiation of antigen-specific cytotoxic $\mathrm{T}$ lymphocytes," International Immunology, vol. 12, no. 7, pp. 987-994, 2000.

[182] L. S. Metelitsa, O. V. Naidenko, A. Kant et al., "Human NKT cells mediate antitumor cytotoxicity directly by recognizing target cell CD1d with bound ligand or indirectly by producing IL-2 to activate NK cells," Journal of Immunology, vol. 167, no. 6, pp. 3114-3122, 2001.

[183] M. Brigl and M. B. Brenner, "CD1: antigen presentation and T cell function," Annual Review of Immunology, vol. 22, pp. 817-890, 2004.

[184] W. Song, H. J. J. Van Der Vliet, Y. T. Tai et al., "Generation of antitumor invariant natural killer T cell lines in multiple myeloma and promotion of their functions via lenalidomide: a strategy for immunotherapy," Clinical Cancer Research, vol. 14, no. 21, pp. 6955-6962, 2008.

[185] E. Kastritis, A. Charidimou, A. Varkaris, and M. A. Dimopoulos, "Targeted therapies in multiple myeloma," Targeted Oncology, vol. 4, no. 1, pp. 23-36, 2009.

[186] P. Kapoor, P. T. Greipp, W. G. Morice, S. V. Rajkumar, T. E. Witzig, and P. R. Greipp, "Anti-CD20 monoclonal antibody therapy in multiple myeloma," British Journal of Haematology, vol. 141, no. 2, pp. 135-148, 2008.

[187] N. Robillard, H. Avet-Loiseau, R. Garand et al., "CD20 is associated with a small mature plasma cell morphology and $\mathrm{t}(11 ; 14)$ in multiple myeloma," Blood, vol. 102, no. 3, pp. 1070-1071, 2003.

[188] U. Schonbeck and P. Libby, "The CD40/CD154 receptor/ligand dyad," Cellular and Molecular Life Sciences, vol. 58, no. 1, pp. 4-43, 2001.

[189] J. Banchereau, F. Bazon, D. Blanchard et al., "The CD40 antigen and its ligand," Annual Review of Immunology, vol. 12, pp. 881-922, 1994.

[190] G. Van Kooten and J. Banchereau, "CD40-CD40 ligand," Journal of Leukocyte Biology, vol. 67, no. 1, pp. 2-17, 2000.

[191] C. Pellat-Deceunynck, R. Bataille, N. Robillard et al., "Expression of CD28 and CD40 in human myeloma cells: a comparative study with normal plasma cells," Blood, vol. 84, no. 8, pp. 2597-2603, 1994.

[192] Y. T. Tai, K. Podar, N. Mitsiades et al., “CD40 induces human multiple myeloma cell migration via phosphatidylinositol 3-kinase/AKT/NF- $\kappa$ B signaling," Blood, vol. 101, no. 7, pp. 2762-2769, 2003.

[193] Y. T. Tai, K. Podar, D. Gupta et al., "CD40 activation induces p53-dependent vascular endothelial growth factor secretion in human multiple myeloma cells," Blood, vol. 99, no. 4, pp. 1419-1427, 2002.

[194] M. Urashima, D. Chauhan, M. Hatziyanni et al., "CD40 ligand triggers interleukin-6 mediated B cell differentiation," Leukemia Research, vol. 20, no. 6, pp. 507-515, 1996.

[195] C. L. Law, K. A. Gordon, J. Collier et al., "Preclinical antilymphoma activity of a humanized anti-CD40 monoclonal antibody, SGN-40," Cancer Research, vol. 65, no. 18, pp. 8331-8338, 2005.

[196] Y. T. Tai, L. P. Catley, C. S. Mitsiades et al., "Mechanisms by which SGN-40, a humanized anti-CD40 antibody, induces cytotoxicity in human multiple myeloma cells: clinical implications," Cancer Research, vol. 64, no. 8, pp. 2846-2852, 2004.

[197] T. Hayashi, S. P. Treon, T. Hideshima et al., "Recombinant humanized anti-CD40 monoclonal antibody triggers autologous antibody-dependent cell-mediated cytotoxicity against multiple myeloma cells," British Journal of Haematology, vol. 121, no. 4, pp. 592-596, 2003.

[198] Y. T. Tai, X. Li, X. Tong et al., "Human anti-CD40 antagonist antibody triggers significant antitumor activity against human multiple myeloma," Cancer Research, vol. 65, no. 13, pp. 5898-5906, 2005.

[199] H. M. Horton, M. J. Bernett, M. Peipp et al., "Fc-engineered anti-CD40 antibody enhances multiple effector functions and exhibits potent in vitro and in vivo antitumor activity against hematologic malignancies," Blood, vol. 116, no. 16, pp. 3004-3012, 2010.

[200] Y. T. Tai, X. F. Li, L. Catley et al., "Immunomodulatory drug lenalidomide (CC-5013, IMiD3) augments anti-CD40 SGN40-induced cytotoxicity in human multiple myeloma: clinical implications," Cancer Research, vol. 65, no. 24, pp. 11712 11720, 2005.

[201] E. Agura, R. Niesvizky, J. Matous et al., "Dacetuzumab (SGN40 ), lenalidomide, and weekly dexamethasone in relapsed or refractory multiple myeloma: multiple responses observed in a phase 1b study," Blood, vol. 114, no. 22, abstract 2870, 2009.

[202] E. M. Ocio, M. V. Mateos, P. Maiso, A. Pandiella, and J. F. SanMiguel, "New drugs in multiple myeloma: mechanisms of action and phase I/II clinical findings," The Lancet Oncology, vol. 9, no. 12, pp. 1157-1165, 2008.

[203] Y. T. Tai, M. Dillon, W. Song et al., "Anti-CSl humanized monoclonal antibody HuLuc63 inhibits myeloma cell adhesion and induces antibody-dependent cellular cytotoxicity in the bone marrow milieu," Blood, vol. 112, no. 4, pp. 13291337, 2008.

[204] Y. T. Tai, E. Soydan, W. Song et al., "CS1 promotes multiple myeloma cell adhesion, clonogenic growth, and tumorigenicity via c-maf-mediated interactions with bone marrow stromal cells," Blood, vol. 113, no. 18, pp. 4309-4318, 2009.

[205] E. D. Hsi, R. Steinle, B. Balasa et al., "CS1, a potential new therapeutic antibody target for the treatment of multiple myeloma," Clinical Cancer Research, vol. 14, no. 9, pp. 27752784, 2008.

[206] A. Rice, M. Dillon, A. van Abbema et al., "Eradication of tumors in pre-clinical models of multiple myeloma by antiCS1 monoclonal antibody HuLuc63: mechanism of action studies," Blood, vol. 108, no. 11, abstract 3503, 2006.

[207] W. Bensinger, J. Zonder, S. Singhal et al., "Phase I trial of HuLuc63 in multiple myeloma," Blood, vol. 110, no. 11, abstract 1180, 2007.

[208] J.A. Zonder, S. Singhal, W. Bensinger et al., "Phase I study of elotuzumab (HuLuc63) in relapsed/refractory multiple myeloma," Blood, vol. 112, no. 11, abstract 2773, 2008.

[209] A. J. Jakubowiak, D. M. Benson Jr., W. Bensinger et al., "Elotuzumab in combination with bortezomib in patients with relapsed/refractory multiple myeloma: updated results of a phase 1 study," Blood, vol. 116, no. 21, abstract 3023, 2010.

[210] S. Lonial, R. Vij, J.-L. Harousseau et al., "Elotuzumab in combination with lenalidomide and low-dose dexamethasone in patients with relasped/refractory multiple myeloma: results of a phase 1 study," Blood, vol. 116, no. 21, abstract 1936, 2010.

[211] P. G. Richardson, P. Moreau, A. J. Jakubowiak et al., "Elotuzumab in combination with lenalidomide and dexamethasone in patients with relapsed multiple myeloma: interim results of a phase 2 study," Blood, vol. 116, no. 21, abstract 986, 2010. 
[212] J. Wijdenes, W. C. Vooijs, C. Clément et al., "A plasmocyte selective monoclonal antibody (B-B4) recognizes syndecan1," British Journal of Haematology, vol. 94, no. 2, pp. 318-323, 1996.

[213] M. V. Dhodapkar, T. Kelly, A. Theus, A. B. Athota, B. Barlogie, and R. D. Sanderson, "Elevated levels of shed syndecan-1 correlate with tumour mass and decreased matrix metalloproteinase- 9 activity in the serum of patients with multiple myeloma," British Journal of Haematology, vol. 99, no. 2, pp. 368-371, 1997.

[214] I. B. Bayer-Garner, R. D. Sanderson, M. V. Dhodapkar, R. B. Owens, and C. S. Wilson, "Syndecan-1 (CD138) immunoreactivity in bone marrow biopsies of multiple myeloma: shed syndecan-1 accumulates in fibrotic regions," Modern Pathology, vol. 14, no. 10, pp. 1052-1058, 2001.

[215] C. Seidel, A. Sundan, M. Hjorth et al., "Serum syndecan-1: a new independent prognostic marker in multiple myeloma," Blood, vol. 95, no. 2, pp. 388-392, 2000.

[216] Y. Yang, S. Yaccoby, W. Liu et al., "Soluble syndecan-1 promotes growth of myeloma tumors in vivo," Blood, vol. 100, no. 2, pp. 610-617, 2002.

[217] J. Post, W. C. Vooijs, B. J. Bast, and G. C. De Gast, "Efficacy of an anti-CD138 immunotoxin and doxorubicin on drugresistant and drug-sensitive myeloma cells," International Journal of Cancer, vol. 83, no. 4, pp. 571-576, 1999.

[218] L. Ragnarsson, T. Strömberg, J. Wijdenes, T. H. Tötterman, and C. Weigelt, "Multiple myeloma cells are killed by syndecan-1-directed superantigen-activated T cells," Cancer Immunology, Immunotherapy, vol. 50, no. 7, pp. 382-390, 2001.

[219] P. Tassone, V. S. Goldmacher, P. Neri et al., "Cytotoxic activity of the maytansinoid immunoconjugate B-B4-DM1 against CD138+ multiple myeloma cells," Blood, vol. 104, no. 12, pp. 3688-3696, 2004.

[220] R. Stein, M. J. Mattes, T. M. Cardillo et al., "CD74: a new candidate target for the immunotherapy of B-cell neoplasms," Clinical Cancer Research, vol. 13, no. 18, 2007.

[221] R. Stein, Z. Qu, T. M. Cardillo et al., "Antiproliferative activity of a humanized anti-CD74 monoclonal antibody, hLL1, on B-cell malignancies," Blood, vol. 104, no. 12, pp. 3705-3711, 2004.

[222] P. Sapra, R. Stein, J. Pickett et al., "Anti-CD74 antibodydoxorubicin conjugate, IMMU-110, in a human multiple myeloma xenograft and in monkeys," Clinical Cancer Research, vol. 11, no. 14, pp. 5257-5264, 2005.

[223] A. M. Florena, C. Tripodo, L. Miceli, S. Ingrao, R. Porcasi, and V. Franco, "Identification of CD162 in plasma-cell dyscrasia," Lancet Oncology, vol. 6, no. 8, p. 632, 2005.

[224] C. Tripodo, A. M. Florena, P. Macor et al., "P-selectin glycoprotein ligand-1 as a potential target for humoral immunotherapy of multiple myeloma," Current Cancer Drug Targets, vol. 9, no. 5, pp. 617-625, 2009.

[225] M. Ringhoffer, N. Blumstein, B. Neumaier et al., " 188 Re or 90Y-labelled anti-CD66 antibody as part of a dose-reduced conditioning regimen for patients with acute leukaemia or myelodysplastic syndrome over the age of 55: results of a phase I-II study," British Journal of Haematology, vol. 130, no. 4, pp. 604-613, 2005.

[226] M. M. Zhang and A. K. Gopal, "Radioimmunotherapybased conditioning regimens for stem cell transplantation," Seminars in Hematology, vol. 45, no. 2, pp. 118-125, 2008.

[227] C. Lee, B. A. Guinn, S. E. Brooks, D. Richardson, and K. Orchard, "CD66a (CEACAM1) is the only CD66 variant expressed on the surface of plasma cells in multiple myeloma: a refined target for radiotherapy trials?" British Journal of Haematology, vol. 149, no. 5, pp. 795-797, 2010.

[228] P. J. Bjorkman and W. P. Burmeister, "Structures of two classes of MHC molecules elucidated: crucial differences and similarities," Current Opinion in Structural Biology, vol. 4, no. 6, pp. 852-856, 1994.

[229] E. H. Cooper and T. Plesner, "Beta-2-microglobulin review: its relevance in clinical oncology," Medical and Pediatric Oncology, vol. 8, no. 4, pp. 323-334, 1980.

[230] B. Barlogie, S. Jagannath, K. R. Desikan et al., "Total therapy with tandem transplants for newly diagnosed multiple myeloma," Blood, vol. 93, no. 1, pp. 55-65, 1999.

[231] J. Yang, J. Qian, M. Wezeman et al., "Targeting $\beta 2$-microglobulin for induction of tumor apoptosis in human hematological malignancies," Cancer Cell, vol. 10, no. 4, pp. 295-307, 2006.

[232] J. Yang, X. Zhang, J. Wang et al., "Anti- $\beta 2$-microglobulin monoclonal antibodies induce apoptosis in myeloma cells by recruiting MHC class I to and excluding growth and survival cytokine receptors from lipid rafts," Blood, vol. 110, no. 8, pp. 3028-3035, 2007.

[233] E. Sekimoto, S. Ozaki, T. Ohshima et al., "A single-chain Fv diabody against human leukocyte antigen-A molecules specifically induces myeloma cell death in the bone marrow environment," Cancer Research, vol. 67, no. 3, pp. 1184-1192, 2007.

[234] S. Deaglio, K. Mehta, and F. Malavasi, "Human CD38: a (r)evolutionary story of enzymes and receptors," Leukemia Research, vol. 25, no. 1, pp. 1-12, 2001.

[235] F. K. Stevenson, A. J. Bell, R. Cusack et al., "Preliminary studies for an immunotherapeutic approach to the treatment of human myeloma using chimeric anti-CD38 antibody," Blood, vol. 77, no. 5, pp. 1071-1079, 1991.

[236] J. H. Ellis, K. A. Barber, A. Tutt et al., "Engineered anti-CD38 monoclonal antibodies for immunotherapy of multiple myeloma," Journal of Immunology, vol. 155, no. 2, pp. 925937, 1995.

[237] P. Lin, R. Owens, G. Tricot, and C. S. Wilson, "Flow Cytometric Immunophenotypic Analysis of 306 Cases of Multiple Myeloma," American Journal of Clinical Pathology, vol. 121, no. 4, pp. 482-488, 2004.

[238] C. Osipo and L. Miele, "Hedgehog signaling in hepatocellular carcinoma: novel therapeutic strategy targeting Hedgehog signaling in HCC," Cancer Biology and Therapy, vol. 5, no. 2, pp. 238-239, 2006.

[239] M. De Weers, Y. T. Tai, M. S. Van Der Veer et al., "Daratumumab, a novel therapeutic human CD38 monoclonal antibody, induces killing of multiple myeloma and other hematological tumors," Journal of Immunology, vol. 186, no. 3, pp. 1840-1848, 2011.

[240] M. S. van der Veer, M. de Weers, B. van Kessel et al., "Towards effective immunotherapy of myeloma enhanced elimination of myeloma cells by combination of lenalidomide with the human CD38 monoclonal antibody daratumumab," Haematologica, vol. 96, no. 2, pp. 284-290, 2011.

[241] B. Hardy, R. Kovjazin, A. Raiter, N. Ganor, and A. Novogrodsky, "A lymphocyte-activating monoclonal antibody induces regression of human tumors in severe combined immunodeficient mice," Proceedings of the National Academy of Sciences of the United States of America, vol. 94, no. 11, pp. 5756-5760, 1997.

[242] R. Berger, R. Rotem-Yehudar, G. Slama et al., "Phase i safety and pharmacokinetic study of CT-011, a humanized antibody interacting with PD-1, in patients with advanced 
hematologic malignancies," Clinical Cancer Research, vol. 14, no. 10, pp. 3044-3051, 2008.

[243] M. Trikha, R. Corringham, B. Klein, and J. F. Rossi, “Targeted anti-interleukin- 6 monoclonal antibody therapy for cancer: a review of the rationale and clinical evidence," Clinical Cancer Research, vol. 9, no. 13, pp. 4653-4665, 2003.

[244] J.-F. Rossi, R. F. Manges, H. J. Sutherland et al., "Preliminary results of CNTO 328, an anti-interleukin-6 monoclonal antibody, in combination with bortezomib in the treatment of relapsed or refractory multiple myeloma," Blood, vol. 112, no. 11, abstract 867, 2008.

[245] P. Moreau, J. L. Harousseau, J. Wijdenes, N. Morineau, N. Milpied, and R. Bataille, "A combination of anti-interleukin 6 murine monoclonal antibody with dexamethasone and high-dose melphalan induces high complete response rates in advanced multiple myeloma," British Journal of Haematology, vol. 109, no. 3, pp. 661-664, 2000.

[246] P. Moreau, C. Hullin, F. Garban et al., "Tandem autologous stem cell transplantation in high-risk de novo multiple myeloma: final results of the prospective and randomized IFM 99-04 protocol," Blood, vol. 107, no. 1, pp. 397-403, 2006.

[247] N. Yoshio-Hoshino, Y. Adachi, C. Aoki, A. Pereboev, D. T. Curiel, and N. Nishimoto, "Establishment of a new interleukin-6 (IL-6) receptor inhibitor applicable to the gene therapy for IL-6-dependent tumor," Cancer Research, vol. 67, no. 3, pp. 871-875, 2007.

[248] M. Fulciniti, T. Hideshima, C. Vermot-Desroches et al., "A high-affinity fully human anti-IL-6 mAb, 1339, for the treatment of multiple myeloma," Clinical Cancer Research, vol. 15, no. 23, pp. 7144-7152, 2009.

[249] M. Raschko, S. Markovina, S. Miyamoto et al., "Phase II trial of bevacizumab combined with low dose dexamethasone and lenalidomide (BEV/REV/DEX) for relapsed or refractory myeloma (MM)," Blood, vol. 110, no. 11, abstract 1173, 2007.

[250] N. S. Callander, S. Markovina, and M. B. Juckett, "The addition of bevacizumab (B) to lenalidomide and low dose dexamethasone does not significantly increase response in relapsed or refractory multiple myeloma (NCI\#7317)," Blood, vol. 114, no. 22, abstract 3885, 2009.

[251] D. M. Weber, C. Chen, R. Niesvizky et al., "Lenalidomide plus dexamethasone for relapsed multiple myeloma in North America," The New England Journal of Medicine, vol. 357, no. 21, pp. 2133-2142, 2007.

[252] T. Ishii, A. Chanan-Khan, J. Jafferjee et al., "A humanized anti-ganglioside GM2 antibody, BIW-8962, exhibits ADCC/CDC activity against multiple myeloma cells and potent anti-tumor activity in mouse xenograft models," Blood, vol. 112, no. 11, abstract 1718, 2008.

[253] J. Moreaux, D. Hose, T. Reme et al., "CD200 is a new prognostic factor in multiple myeloma," Blood, vol. 108, no. 13, pp. 4194-4197, 2006.

[254] K. S. Campbell and A. K. Purdy, "Structure/function of human killer cell immunoglobulin-like receptors: lessons from polymorphisms, evolution, crystal structures and mutations," Immunology, vol. 132, no. 3, pp. 315-325, 2011.

[255] J. M. Lambert, "Drug-conjugated monoclonal antibodies for the treatment of cancer," Current Opinion in Pharmacology, vol. 5, no. 5, pp. 543-549, 2005.

[256] P. D. Senter, "Potent antibody drug conjugates for cancer therapy," Current Opinion in Chemical Biology, vol. 13, no. 3, pp. 235-244, 2009.
[257] R. V. J. Chari, “Targeted cancer therapy: conferring specificity to cytotoxic drugs," Accounts of Chemical Research, vol. 41, no. 1, pp. 98-107, 2008.

[258] R. J. Lutz and K. R. Whiteman, "Antibody-maytansinoid conjugates for the treatment of myeloma," $m A b s$, vol. 1, no. 6, pp. 548-551, 2009.

[259] H. K. Erickson, P. U. Park, W. C. Widdison et al., "Antibodymaytansinoid conjugates are activated in targeted cancer cells by lysosomal degradation and linker-dependent intracellular processing," Cancer Research, vol. 66, no. 8, pp. 4426-4433, 2006.

[260] J. D. Griffin, T. Hercend, R. Beveridge, and S. F. Schlossman, "Characterization of an antigen expressed by human natural killer cells," Journal of Immunology, vol. 130, no. 6, pp. 29472951, 1983.

[261] L. L. Lanier, A. M. Le, and C. I. Civin, "The relationship of CD16 (Leu-11) and Leu-19 (NKH-1) antigen expression on human peripheral blood NK cells and cytotoxic $\mathrm{T}$ lymphocytes," Journal of Immunology, vol. 136, no. 12, pp. 4480-4486, 1986.

[262] H. Harada, M. M. Kawano, N. Huang et al., "Phenotypic difference of normal plasma cells from mature myeloma cells," Blood, vol. 81, no. 10, pp. 2658-2663, 1993.

[263] P. Tassone, A. Gozzini, V. Goldmacher et al., "In vitro and in vivo activity of the maytansinoid immunoconjugate huN901-N2' -deacetyl-N2' - (3-mercapto-1- oxopropyl)maytansine against CD56+ multiple myeloma cells," Cancer Research, vol. 64, no. 13, pp. 4629-4636, 2004.

[264] A. C. Rawstron, R. G. Owen, F. E. Davies et al., "Circulating plasma cells in multiple myeloma: characterization and correlation with disease stage," British Journal of Haematology, vol. 97, no. 1, pp. 46-55, 1997.

[265] N. Sahara, A. Takeshita, K. Shigeno et al., "Clinicopathological and prognostic characteristics of CD56-negative multiple myeloma," British Journal of Haematology, vol. 117, no. 4, pp. 882-885, 2002.

[266] S. A. Ely and D. M. Knowles, "Expression of CD56/neural cell adhesion molecule correlates with the presence of lytic bone lesions in multiple myeloma and distinguishes myeloma from monoclonal gammopathy of undetermined significance and lymphomas with plasmacytoid differentiation," American Journal of Pathology, vol. 160, no. 4, pp. 1293-1299, 2002.

[267] R. A. O. Lutz, K. Foley, V. Goldmacher et al., "Efficacy of the huN901-DM1 conjugate in combination with antineoplastic agents against multiple myeloma cells in preclinical studies," AACR Meeting Abstracts, 2007.

[268] K. A. O. Whiteman, L. Bartle, K. Foley et al., "Efficacy of IMGN901 (huN901-DM1) in combination with bortezomib and lenalidomide against multiple myeloma cells in preclinical studies," AACR, 2008.

[269] H. Ikeda, T. Hideshima, M. Fulciniti et al., "The monoclonal antibody nBT062 conjugated to cytotoxic maytansinoids has selective cytotoxicity against CD138-positive multiple myeloma cells in vitro and in vivo," Clinical Cancer Research, vol. 15, no. 12, pp. 4028-4037, 2009.

[270] A. Palumbo and K. Anderson, "Multiple myeloma," The New England Journal of Medicine, vol. 364, no. 11, pp. 1046-1060, 2011.

[271] G. D. Roodman, "Pathogenesis of myeloma bone disease," Blood Cells, Molecules, and Diseases, vol. 32, no. 2, pp. 290292, 2004.

[272] O. Sezer, "Myeloma bone disease," Hematology, vol. 10, no. 1, pp. 19-24, 2005. 
[273] T. Hideshima, C. Mitsiades, G. Tonon, P. G. Richardson, and K. C. Anderson, "Understanding multiple myeloma pathogenesis in the bone marrow to identify new therapeutic targets," Nature Reviews Cancer, vol. 7, no. 8, pp. 585-598, 2007.

[274] R. E. Coleman, P. Major, A. Lipton et al., "Predictive value of bone resorption and formation markers in cancer patients with bone metastases receiving the bisphosphonate zoledronic acid," Journal of Clinical Oncology, vol. 23, no. 22, pp. 4925-4935, 2005.

[275] R. N. Pearse, E. M. Sordillo, S. Yaccoby et al., "Multiple myeloma disrupts the TRANCE/osteoprotegerin cytokine axis to trigger bone destruction and promote tumor progression," Proceedings of the National Academy of Sciences of the United States of America, vol. 98, no. 20, pp. 11581-11586, 2001.

[276] K. Vanderkerken, E. De Leenheer, C. Shipman et al., "Recombinant osteoprotegerin decreases tumor burden and increases survival in a murine model of multiple myeloma," Cancer Research, vol. 63, no. 2, pp. 287-289, 2003.

[277] G. Pratt, O. Goodyear, and P. Moss, "Immunodeficiency and immunotherapy in multiple myeloma," British Journal of Haematology, vol. 138, no. 5, pp. 563-579, 2007.

[278] M. S. Filla, P. Dam, and A. C. Rapraeger, "The cell surface proteoglycan syndecan-1 mediates fibroblast growth factor-2 binding and activity," Journal of Cellular Physiology, vol. 174, no. 3, pp. 310-321, 1998.

[279] L. Jakobsson, J. Kreuger, K. Holmborn et al., "Heparan Sulfate in trans Potentiates VEGFR-Mediated Angiogenesis," Developmental Cell, vol. 10, no. 5, pp. 625-634, 2006.

[280] S. Lamorte, S. Ferrero, S. Aschero et al., "Syndecan-1 promotes the angiogenic phenotype of multiplemyeloma endothelial cells," Leukemia. In press.

[281] R. D. Sanderson, Y. Yang, T. Kelly, V. MacLeod, Y. Dai, and A. Theus, "Enzymatic remodeling of heparan sulfate proteoglycans within the tumor microenvironment: growth regulation and the prospect of new cancer therapies," Journal of Cellular Biochemistry, vol. 96, no. 5, pp. 897-905, 2005.

[282] I. Vlodavsky, O. Goldshmidt, E. Zcharia et al., "Mammalian heparanase: involvement in cancer metastasis, angiogenesis and normal development," Seminars in Cancer Biology, vol. 12, no. 2, pp. 121-129, 2002.

[283] Y. Dai, Y. Yang, V. MacLeod et al., "HSulf-1 and HSulf-2 are potent inhibitors of myeloma tumor growth in vivo," Journal of Biological Chemistry, vol. 280, no. 48, pp. 40066-40073, 2005.

[284] Y. Yang, V. MacLeod, Y. Dai et al., "The syndecan-1 heparan sulfate proteoglycan is a viable target for myeloma therapy," Blood, vol. 110, no. 6, pp. 2041-2048, 2007.

[285] O. Ostrovsky, M. Korostishevsky, I. Levite et al., "Association of heparanase gene (HPSE) single nucleotide polymorphisms with hematological malignancies," Leukemia, vol. 21, no. 11, pp. 2296-2303, 2007.

[286] H. B. Huang and R. Zhan, "Effect of VEGF antisense RNA on inducing apoptosis of myeloma cells and inhibition of angiogenesis in endothelial cells in vitro," Zhongguo Shi Yan Xue Ye Xue Za Zhi, vol. 16, no. 2, pp. 312-316, 2008.

[287] K. Podar, A. Zimmerhackl, M. Fulciniti et al., "The selective adhesion molecule inhibitor Natalizumab decreases multiple myeloma cell growth in the bone marrow microenvironment: therapeutic implications," British Journal of Haematology, vol. 155 , no. 4, pp. 438-448, 2011.
[288] S. Gardam and R. Beyaert, "The kinase NIK as a therapeutic target in multiple myeloma," Expert Opinion on Therapeutic Targets, vol. 15, no. 2, pp. 207-218, 2011.

[289] K. Tozawa, M. Sagawa, and M. Kizaki, "Quinone methide tripterine, celastrol, induces apoptosis in human myeloma cells via NF- $\kappa$ B pathway," International Journal of Oncology, vol. 39, no. 5, pp. 1117-1122, 2011.

[290] L. Chen, C. Li, R. Zhang et al., "MiR-17-92 cluster microRNAs confers tumorigenicity in multiple myeloma," Cancer Letters, vol. 309, no. 1, pp. 62-70, 2011.

[291] F. Pichiorri, S. S. Suh, M. Ladetto et al., "MicroRNAs regulate critical genes associated with multiple myeloma pathogenesis," Proceedings of the National Academy of Sciences of the United States of America, vol. 105, no. 35, pp. 1288512890, 2008.

[292] R. Vij, N. Horvath, A. Spencer et al., "An open-label, phase 2 trial of denosumab in the treatment of relapsed or plateauphase multiple myeloma," American Journal of Hematology, vol. 84, no. 10, pp. 650-656, 2009.

[293] E. Tian, F. Zhan, R. Walker et al., "The Role of the WntSignaling Antagonist DKK1 in the Development of Osteolytic Lesions in Multiple Myeloma," The New England Journal of Medicine, vol. 349, no. 26, pp. 2483-2494, 2003.

[294] N. Giuliani, F. Morandi, S. Tagliaferri et al., "Production of Wnt inhibitors by myeloma cells: potential effects on canonical Wnt pathway in the bone microenvironment," Cancer Research, vol. 67, no. 16, pp. 7665-7674, 2007.

[295] Y. W. Qiang, B. Barlogie, S. Rudikoff, and J. D. Shaughnessy, "Dkk1-induced inhibition of Wnt signaling in osteoblast differentiation is an underlying mechanism of bone loss in multiple myeloma," Bone, vol. 42, no. 4, pp. 669-680, 2008.

[296] J. Qian, J. Xie, S. Hong et al., "Dickkopf-1 (DKK1) is a widely expressed and potent tumor-associated antigen in multiple myeloma," Blood, vol. 110, no. 5, pp. 1587-1594, 2007.

[297] M. Fulciniti, P. Tassone, T. Hideshima et al., "Anti-DKK1 $\mathrm{mAb}(\mathrm{BHQ} 880)$ as a potential therapeutic agent for multiple myeloma," Blood, vol. 114, no. 2, pp. 371-379, 2009.

[298] D. J. Heath, A. D. Chantry, C. H. Buckle et al., "Inhibiting dickkopf-1 (Dkkl) removes suppression of bone formation and prevents the development of osteolytic bone disease in multiple myeloma," Journal of Bone and Mineral Research, vol. 24, no. 3, pp. 425-436, 2009.

[299] V. Kunzmann, E. Bauer, J. Feurle, F. Weißinger, H. P. Tony, and M. Wilhelm, "Stimulation of $\gamma \delta \mathrm{T}$ cells by aminobisphosphonates and induction of antiplasma cell activity in multiple myeloma," Blood, vol. 96, no. 2, pp. 384-392, 2000.

[300] F. Dieli, D. Vermijlen, F. Fulfaro et al., "Targeting human $\gamma \delta \mathrm{T}$ cells with zoledronate and interleukin-2 for immunotherapy of hormone-refractory prostate cancer," Cancer Research, vol. 67, no. 15, pp. 7450-7457, 2007.

[301] A. Märten, M. Lilienfeld-Toal, M. W. Büchler, and J. Schmidt, "Zoledronic acid has direct antiproliferative and antimetastatic effect on pancreatic carcinoma cells and acts as an antigen for delta2 gamma/delta T cells," Journal of Immunotherapy, vol. 30, no. 4, pp. 370-377, 2007.

[302] S. R. Mattarollo, T. Kenna, M. Nieda, and A. J. Nicol, "Chemotherapy and zoledronate sensitize solid tumour cells to Vgamma9Vdelta2 T cell cytotoxicity," Cancer Immunology, Immunotherapy, vol. 56, no. 8, pp. 1285-1297, 2007.

[303] M. Wilhelm, V. Kunzmann, S. Eckstein et al., " $\gamma \delta$ T cells for immune therapy of patients with lymphoid malignancies," Blood, vol. 102, no. 1, pp. 200-206, 2003. 
[304] Y. Abe, M. Muto, M. Nieda et al., "Clinical and immunological evaluation of zoledronate-activated $\mathrm{V} \gamma 9 \gamma \delta$ T-cellbased immunotherapy for patients with multiple myeloma," Experimental Hematology, vol. 37, no. 8, pp. 956-968, 2009.

[305] M. Pevsner-Fischer, V. Morad, M. Cohen-Sfady et al., "Tolllike receptors and their ligands control mesenchymal stem cell functions," Blood, vol. 109, no. 4, pp. 1422-1432, 2007.

[306] H. C. Hyun, C. B. Yong, and S. J. Jin, "Role of toll-like receptors on human adipose-derived stromal cells," Stem Cells, vol. 24, no. 12, pp. 2744-2752, 2006.

[307] E. Lombardo, O. Delarosa, P. Mancheño-Corvo, R. Menta, C. Ramírez, and D. Büscher, "Toll-like receptor-mediated signaling in human adipose-derived stem cells: implications for immunogenicity and immunosuppressive potential," Tissue Engineering A, vol. 15, no. 7, pp. 1579-1589, 2009.

[308] I. F. Y. Mo, K. H. K. Yip, W. K. Chan, H. K. W. Law, Y. L. Lau, and G. C. F. Chan, "Prolonged exposure to bacterial toxins downregulated expression of toll-like receptors in mesenchymal stromal cell-derived osteoprogenitors," BMC Cell Biology, vol. 9, article no. 52, 2008.

[309] F. Liotta, R. Angeli, L. Cosmi et al., "Toll-like receptors 3 and 4 are expressed by human bone marrow-derived mesenchymal stem cells and can inhibit their T-cell modulatory activity by impairing notch signaling," Stem Cells, vol. 26, no. 1, pp. 279-289, 2008.

[310] S. L. Tomchuck, K. J. Zwezdaryk, S. B. Coffelt, R. S. Waterman, E. S. Danka, and A. B. Scandurro, "Toll-like receptors on human mesenchymal stem cells drive their migration and immunomodulating responses," Stem Cells, vol. 26, no. 1, pp. 99-107, 2008.

[311] K. Podar, D. Chauhan, and K. C. Anderson, "Bone marrow microenvironment and the identification of new targets for myeloma therapy," Leukemia, vol. 23, no. 1, pp. 10-24, 2009.

[312] K. Todoerti, G. Lisignoli, P. Storti et al., "Distinct transcriptional profiles characterize bone microenvironment mesenchymal cells rather than osteoblasts in relationship with multiple myeloma bone disease," Experimental Hematology, vol. 38, no. 2, pp. 141-153, 2010.

[313] M. Garayoa, J. L. Garcia, C. Santamaria et al., "Mesenchymal stem cells from multiple myeloma patients display distinct genomic profile as compared with those from normal donors," Leukemia, vol. 23, no. 8, pp. 1515-1527, 2009.

[314] T. Guillaume, D. B. Rubinstein, and M. Symann, "Immune reconstitution and immunotherapy after autologous hematopoietic stem cell transplantation," Blood, vol. 92, no. 5, pp. 1471-1490, 1998.

[315] T. Nordøy, A. Husebekk, I. S. Aaberge et al., "Humoral immunity to viral and bacterial antigens in lymphoma patients 4-10 years after high-dose therapy with ABMT. Serological responses to revaccinations according to EBMT guidelines," Bone Marrow Transplantation, vol. 28, no. 7, pp. 681-687, 2001.

[316] F. T. Hakim, S. A. Memon, R. Cepeda et al., "Age-dependent incidence, time course, and consequences of thymic renewal in adults," Journal of Clinical Investigation, vol. 115, no. 4, pp. 930-939, 2005.

[317] S. Rutella, L. Pierelli, G. Bonanno et al., "Immune reconstitution after autologous peripheral blood progenitor cell transplantationEffect of interleukin-15 on T-cell survival and effector functions," Experimental Hematology, vol. 29, no. 12, pp. 1503-1516, 2001.

[318] M. Lindemann, P. Schuett, T. Moritz et al., "Cellular in vitro immune function in multiple myeloma patients after high-dose chemotherapy and autologous peripheral stem cell transplantation [17]," Leukemia, vol. 19, no. 3, pp. 490-492, 2005.

[319] A. M. T. van der Velden, A. M. E. Claessen, H. van VelzenBlad, D. H. Biesma, and G. T. Rijkers, "Development of T cell-mediated immunity after autologous stem cell transplantation: prolonged impairment of antigen-stimulated production of $\gamma$-interferon," Bone Marrow Transplantation, vol. 40, no. 3, pp. 261-266, 2007.

[320] L. F. Porrata, M. A. Gertz, D. J. Inwards et al., "Early lymphocyte recovery predicts superior survival after autologous hematopoietic stem cell transplantation in multiple myeloma or non-Hodgkin lymphoma," Blood, vol. 98, no. 3, pp. 579$585,2001$.

[321] H. Ege, M. A. Gertz, S. N. Markovic et al., "Prediction of survival using absolute lymphocyte count for newly diagnosed patients with multiple myeloma: a retrospective study," British Journal of Haematology, vol. 141, no. 6, pp. 792-798, 2008.

[322] C. Joao, L. F. Porrata, D. J. Inwards et al., "Early lymphocyte recovery after autologous stem cell transplantation predicts superior survival in mantle-cell lymphoma," Bone Marrow Transplantation, vol. 37, no. 9, pp. 865-871, 2006.

[323] L. F. Porrata, D. J. Inwards, S. M. Ansell et al., "Early lymphocyte recovery predicts superior survival after autologous stem cell transplantation in non-Hodgkin lymphoma: a prospective study," Biology of Blood and Marrow Transplantation, vol. 14, no. 7, pp. 807-816, 2008.

[324] A. P. Rapoport, N. A. Aqui, E. A. Stadtmauer et al., "Combination immunotherapy using adoptive T-cell transfer and tumor antigen vaccination on the basis of hTERT and survivin after ASCT for myeloma," Blood, vol. 117, no. 3, pp. 788-797, 2011.

[325] L. Li, C. Yee, and J. A. Beavo, "CD3- and CD28-dependent induction of PDE7 required for T cell activation," Science, vol. 283, no. 5403, pp. 848-849, 1999.

[326] V. A. Boussiotis, G. J. Freeman, P. A. Taylor et al., "p27(kip1) functions as an anergy factor inhibiting interleukin 2 transcription and clonal expansion of alloreactive human and mouse helper T lymphocytes," Nature Medicine, vol. 6, no. 3, pp. 290-297, 2000.

[327] B. L. Levine, W. B. Bernstein, M. Connors et al., "Effects of CD28 Costimulation on Long-Term Proliferation of CD4+ T Cells in the Absence of Exogenous Feeder Cells," Journal of Immunology, vol. 159, no. 12, pp. 5921-5930, 1997.

[328] J. L. Riley and C. H. June, "The CD28 family: a T-cell rheostat for therapeutic control of T-cell activation," Blood, vol. 105, no. 1, pp. 13-21, 2005.

[329] A. P. Rapoport, E. A. Stadtmauer, N. Aqui et al., "Restoration of immunity in lymphopenic individuals with cancer by vaccination and adoptive T-cell transfer," Nature Medicine, vol. 11, no. 11, pp. 1230-1237, 2005.

[330] D. Xu, C. Zheng, S. Bergenbrant et al., "Telomerase activity in plasma cell dyscrasias," British Journal of Cancer, vol. 84, no. 5, pp. 621-625, 2001.

[331] K. D. Wu, L. M. Orme, J. Shaughnessy, J. Jacobson, B. Barlogie, and M. A. S. Moore, "Telomerase and telomere length in multiple myeloma: correlations with disease heterogeneity, cytogenetic status, and overall survival," Blood, vol. 101, no. 12, pp. 4982-4989, 2003.

[332] M. Romagnoli, V. Trichet, C. David et al., "Significant impact of survivin on myeloma cell growth," Leukemia, vol. 21, no. 5, pp. 1070-1078, 2007. 
[333] J. F. Rossi, N. Fegueux, Z. Y. Lu et al., "Optimizing the use of anti-interleukin-6 monoclonal antibody with dexamethasone and $140 \mathrm{mg} / \mathrm{m} 2$ of melphalan in multiple myeloma: results of a pilot study including biological aspects," Bone Marrow Transplantation, vol. 36, no. 9, pp. 771-779, 2005.

[334] M. Steffen, M. Dürken, U. Pichlmeier et al., "Serum interleukin-6 levels during bone marrow transplantation: impact on transplant-related toxicity and engraftment," Bone Marrow Transplantation, vol. 18, no. 2, pp. 301-307, 1996.

[335] M. Condomines, J. L. Veyrune, M. Larroque et al., "Increased plasma-immune cytokines throughout the highdose melphalan-induced lymphodepletion in patients with multiple myeloma: a window for adoptive immunotherapy," Journal of Immunology, vol. 184, no. 2, pp. 1079-1084, 2010.

[336] C. Wrzesinski, C. M. Paulos, L. Gattinoni et al., "Hematopoietic stem cells promote the expansion and function of adoptively transferred antitumor CD8+ T cells," Journal of Clinical Investigation, vol. 117, no. 2, pp. 492-501, 2007.

[337] M. E. Dudley, J. R. Wunderlich, P. F. Robbins et al., "Cancer regression and autoimmunity in patients after clonal repopulation with antitumor lymphocytes," Science, vol. 298, no. 5594, pp. 850-854, 2002.

[338] L. X. Wang, S. Shu, and G. E. Plautz, "Host lymphodepletion augments $\mathrm{T}$ cell adoptive immunotherapy through enhanced intratumoral proliferation of effector cells," Cancer Research, vol. 65, no. 20, pp. 9547-9554, 2005.

[339] A. Kobayashi, H. Hara, M. Ohashi et al., "Allogeneic MHC gene transfer enhances an effective antitumor immunity in the early period of autologous hematopoietic stem cell transplantation," Clinical Cancer Research, vol. 13, no. 24, pp. 7469-7479, 2007.

[340] T. Suzuki, S. Ogawa, K. Tanabe, H. Tahara, R. Abe, and H. Kishimoto, "Induction of antitumor immune response by homeostatic proliferation and CD28 signaling," Journal of Immunology, vol. 180, no. 7, pp. 4596-4605, 2008.

[341] O. Boyman, J. F. Purton, C. D. Surh, and J. Sprent, "Cytokines and T-cell homeostasis," Current Opinion in Immunology, vol. 19, no. 3, pp. 320-326, 2007.

[342] M. M. Sandau, C. J. Winstead, and S. C. Jameson, "IL-15 is required for sustained lymphopenia-driven proliferation and accumulation of CD8 T cells," Journal of Immunology, vol. 179, no. 1, pp. 120-125, 2007.

[343] R. Baccala, D. Witherden, R. Gonzalez-Quintial et al., “ $\gamma \delta \mathrm{T}$ cell homeostasis is controlled by IL-7 and IL- 15 together with subset-specific factors," The Journal of Immunology, vol. 174, no. 8, pp. 4606-4612, 2005.

[344] M. Burjanadzé, M. Condomines, T. Reme et al., "In vitro expansion of gamma delta $\mathrm{T}$ cells with anti-myeloma cell activity by Phosphostim and IL-2 in patients with multiple myeloma," British Journal of Haematology, vol. 139, no. 2, pp. 206-216, 2007.

[345] M. Condomines, P. Quittet, Z. Y. Lu et al., "Functional regulatory $\mathrm{T}$ cells are collected in stem cell autografts by mobilization with high-dose cyclophosphamide and granulocyte colony-stimulating factor," Journal of Immunology, vol. 176, no. 11, pp. 6631-6639, 2006.

[346] C. Choi, M. Witzens, M. Bucur et al., "Enrichment of functional CD8 memory T cells specific for MUC1 in bone marrow of patients with multiple myeloma," Blood, vol. 105, no. 5, pp. 2132-2134, 2005.

[347] S. Belle, F. Han, M. Condomines et al., "Identification of HLA-A2 restricted T-cell epitopes within the conserved region of the immunoglobulin $G$ heavy-chain in patients with multiple myeloma," European Journal of Haematology, vol. 81, no. 1, pp. 26-35, 2008.

[348] K. Tarte and B. Klein, "Dendritic cell-based vaccine: a promising approach for cancer immunotherapy," Leukemia, vol. 13, no. 5, pp. 653-663, 1999.

[349] G. Gahrton, S. Tura, P. Ljungman et al., "Prognostic factors in allogeneic bone marrow transplantation for multiple myeloma," Journal of Clinical Oncology, vol. 13, no. 6, pp. 13121322, 1995.

[350] G. Gahrton, S. Tura, P. Ljungman et al., "Allogeneic bone marrow transplantation in multiple myeloma," The New England Journal of Medicine, vol. 325, no. 18, pp. 1267-1273, 1991.

[351] P. Corradini, C. Voena, C. Tarella et al., "Molecular and clinical remissions in multiple myeloma: role of autologous and allogeneic transplantation of hematopoietic cells," Journal of Clinical Oncology, vol. 17, no. 1, pp. 208-215, 1999.

[352] G. Martinelli, C. Terragna, E. Zamagni et al., "Molecular remission after allogeneic or autologous transplantation of hematopoietic stem cells for multiple myeloma," Journal of Clinical Oncology, vol. 18, no. 11, pp. 2273-2281, 2000.

[353] S. J. Harrison and G. Cook, "Immunotherapy in multiple myeloma-possibility or probability?" British Journal of Haematology, vol. 130, no. 3, pp. 344-362, 2005.

[354] A. Shimoni, I. Hardan, F. Ayuk et al., "Allogenic hematopoietic stem-cell transplantation with reduced-intensity conditioning in patients with refractory and recurrent multiple myeloma: long-term follow-up," Cancer, vol. 116, no. 15, pp. 3621-3630, 2010.

[355] G. Gahrton, H. Svensson, M. Cavo et al., "Progress in allogeneic bone marrow and peripheral blood stem cell transplantation for multiple myeloma: a comparison between transplants performed 1983-93 and 1994-98 at European Group for Blood and Marrow Transplantation centres," British Journal of Haematology, vol. 113, no. 1, pp. 209-216, 2001.

[356] F. Garban, M. Attal, M. Michallet et al., "Prospective comparison of autologous stem cell transplantation followed by dose-reduced allograft (IFM99-03 trial) with tandem autologous stem cell transplantation (IFM99-04 trial) in high-risk de novo multiple myeloma," Blood, vol. 107, no. 9, pp. 3474-3480, 2006.

[357] N. Kröger, H. Einsele, D. Wolff et al., "Myeloablative intensified conditioning regimen with in vivo T-cell depletion (ATG) followed by allografting in patients with advanced multiple myeloma. A phase I/II study of the German study-group multiple myeloma (DSMM)," Bone Marrow Transplantation, vol. 31, no. 11, pp. 973-979, 2003.

[358] N. Kröger, R. Schwerdtfeger, M. Kiehl et al., "Autologous stem cell transplantation followed by a dose-reduced allograft induces high complete remission rate in multiple myeloma," Blood, vol. 100, no. 3, pp. 755-760, 2002.

[359] P. Corradini, M. Cavo, H. Lokhorst et al., "Molecular remission after myeloablative allogeneic stem cell transplantation predicts a better relapse-free survival in patients with multiple myeloma," Blood, vol. 102, no. 5, pp. 1927-1929, 2003.

[360] H. M. Lokhorst, K. Wu, L. F. Verdonck et al., "The occurrence of graft-versus-host disease is the major predictive factor for response to donor lymphocyte infusions in multiple myeloma," Blood, vol. 103, no. 11, pp. 4362-4364, 2004. 
[361] M. Salama, T. Nevill, D. Marcellus et al., "Donor leukocyte infusions for multiple myeloma," Bone Marrow Transplantation, vol. 26, no. 11, pp. 1179-1184, 2000.

[362] F. Ayuk, A. Shimoni, A. Nagler et al., "Efficacy and toxicity of low-dose escalating donor lymphocyte infusion given after reduced intensity conditioning allograft for multiple myeloma [8]," Leukemia, vol. 18, no. 3, pp. 659-662, 2004.

[363] K. S. Peggs, S. Mackinnon, C. D. Williams et al., "Reducedintensity transplantation with in vivo T-cell depletion and adjuvant dose-escalating donor lymphocyte infusions for chemotherapy-sensitive myeloma: limited efficacy of graftversus-tumor activity," Biology of Blood and Marrow Transplantation, vol. 9, no. 4, pp. 257-265, 2003.

[364] N. Kröger, W. Krüger, H. Renges et al., "Donor lymphocyte infusion enhances remission status in patients with persistent disease after allografting for multiple myeloma," British Journal of Haematology, vol. 112, no. 2, pp. 421-423, 2001.

[365] N. Kröger, A. Badbaran, M. Lioznov et al., "Post-transplant immunotherapy with donor-lymphocyte infusion and novel agents to upgrade partial into complete and molecular remission in allografted patients with multiple myeloma," Experimental Hematology, vol. 37, no. 7, pp. 791-798, 2009.

[366] L. W. Kwak, R. Pennington, and D. L. Longo, "Active immunization of murine allogeneic bone marrow transplant donors with B-cell tumor-derived idiotype: a strategy for enhancing the specific antitumor effect of marrow grafts," Blood, vol. 87, no. 7, pp. 3053-3060, 1996.

[367] S. S. Neelapu, N. C. Munshi, S. Jagannath et al., "Tumor antigen immunization of sibling stem cell transplant donors in multiple myeloma," Bone Marrow Transplantation, vol. 36, no. 4, pp. 315-323, 2005.

[368] S. B. Kim, S. Baskar, and L. W. Kwak, "In vitro priming of myeloma antigen-specific allogeneic donor T cells with idiotype pulsed dendritic cells," Leukemia and Lymphoma, vol. 44, no. 7, pp. 1201-1208, 2003. 


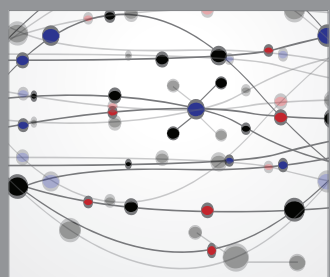

The Scientific World Journal
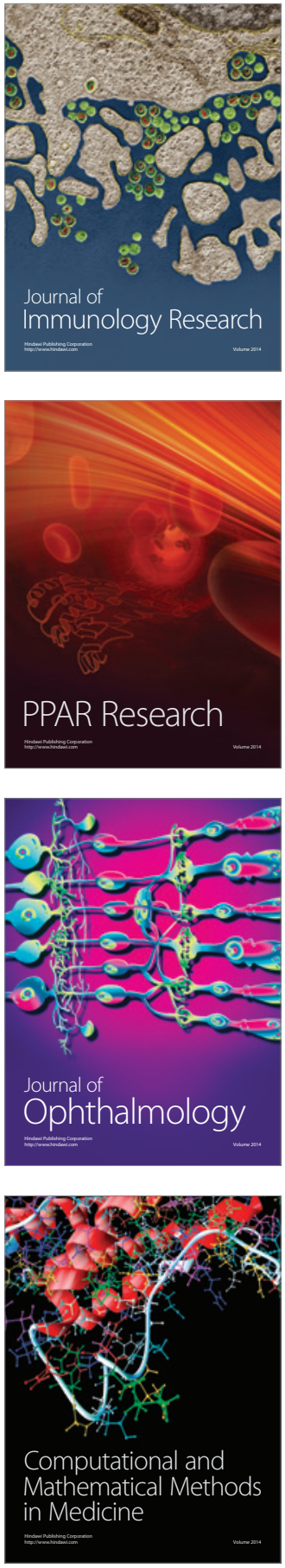

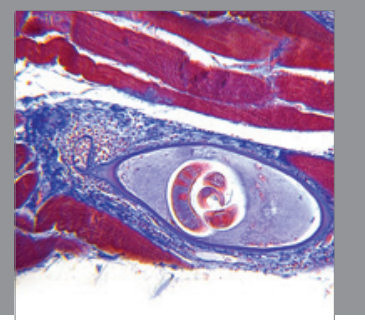

Gastroenterology

Research and Practice
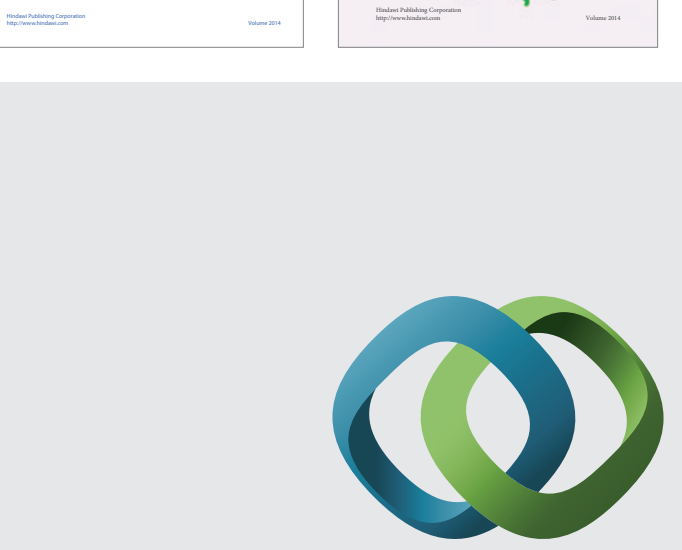

\section{Hindawi}

Submit your manuscripts at

http://www.hindawi.com
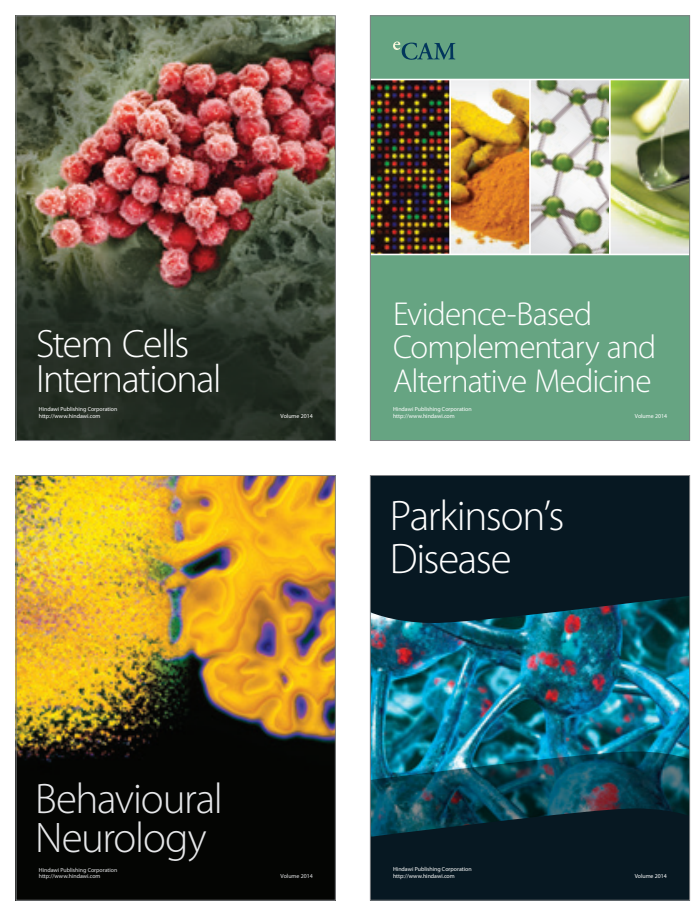

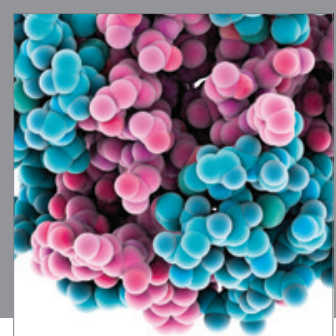

Journal of
Diabetes Research

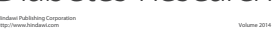

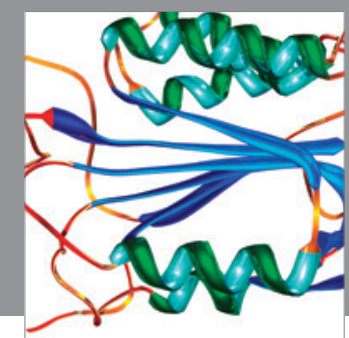

Disease Markers
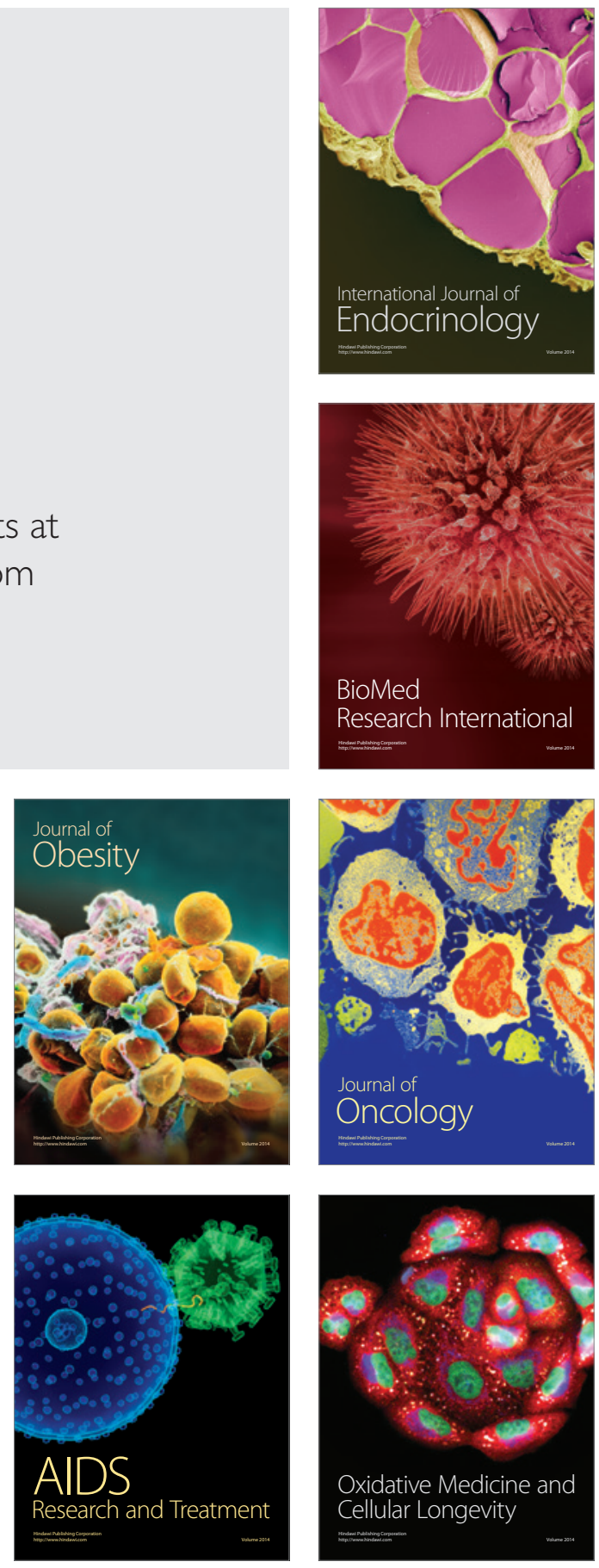